UNIVERSITY OF OKLAHOMA

GRADUATE COLLEGE

THE RELATIONSHIP OF SELF-CONCEALMENT TO BEHAVIORAL INHIBITION AND BEHAVIORAL APPROACH

\author{
A DISSERTATION \\ SUBMITTED TO THE GRADUATE FACULTY \\ in partial fulfillment of the requirements for the \\ Degree of
}

DOCTOR OF PHILOSOPHY

BY

HAYLEY ORNSTEIN

Norman, Oklahoma 2009 


\section{THE RELATIONSHIP OF SELF-CONCEALMENT TO BEHAVIORAL INHIBITION AND BEHAVIORAL APPROACH}

A DISSERTATION APPROVED FOR THE DEPARTMENT OF EDUCATIONAL PSYCHOLOGY

BY

Dr. Cal Stoltenberg, Chair

Dr. Denise Beesley

Dr. Jody Newman

Dr. Rockey Robbins

Dr. Luz-Eugenia Cox-Fuenzalida 
(C) Copyright by HAYLEY ORNSTEIN 2009

All Rights Reserved. 


\section{Acknowledgements}

Many people have helped make the completion of my dissertation possible. I want to thank the individuals who completed my survey and forwarded it on to others. I want to thank my chair, the members of my dissertation committee, and Dr. Mike Crowson. Their time and expertise has helped me overcome difficulties and challenged me to expand and strengthen my understanding of my dissertation topic. I want to thank my teachers and supervisors from graduate school and internship for helping me think critically about myself and the information I examine. I want to thank my classmates for supporting me; they are my models and colleagues with whom I look forward to maintaining professional and personal relationships. I also want to thank all my friends who help me enjoy and maintain balance in my life. I want to thank Melissa and Kayce for their hospitality when I travel to Oklahoma; my brother, Errol, for editing my dissertation; and Desi for reviewing my results. I want to thank my parents for raising me to be open-minded and think critically, values that have helped me in the practice and research of psychology. I finally want to thank my husband, Randy, who has supported me tangibly and emotionally and with whom I look forward to sharing my life as I continue to grow personally and professionally. 


\section{Table of Contents}

Abstract.......................................................................

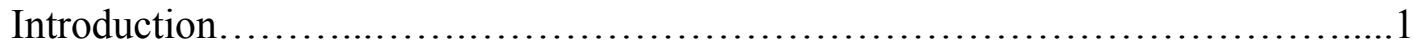

Method................................................................6

Results.............................................................. 67

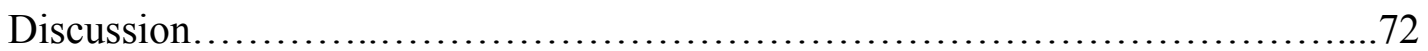

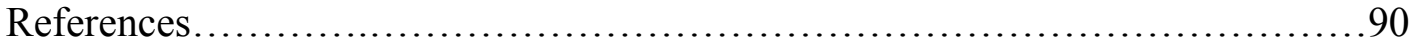

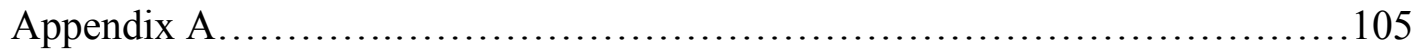

Appendix B........................................................ 106

Appendix C............................................................ 107

Appendix D....................................................... 108

Appendix E.......................................................... 109 


\section{List of Tables}

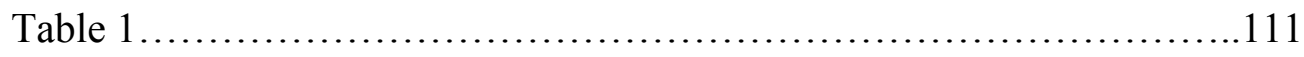

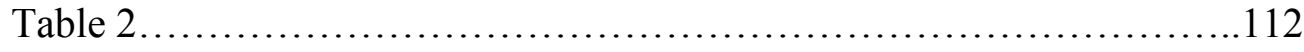

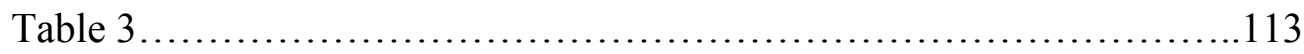




\begin{abstract}
This research examines self-concealment, or the tendency to keep negative information about oneself secret. It reviews research on self-concealment and its positive association to physical and psychological complaints. Theories that claim self-concealment causes these negative symptoms are called into question. An alternative theory is presented, which suggests that the personality of selfconcealers, rather than secret-keeping, per se, primarily contributes to their negative symptomatology (Kelly \& Yip, 2006). This study investigates the relationship between self-concealment and behavioral inhibition, a construct previously suggested as responsible for the association between self-concealment and negative symptomatology (Kelly, 2002; Larson \& Chastain, 1990). This author also investigates the relationship between self-concealment and behavioral approach. The Self-Concealment Scale (SCS; Larson \& Chastain, 1990) and the Behavioral Inhibition/Behavioral Activation Scales (BIS/BAS; Carver \& White, 1994) are used to investigate these questions with a nonclinical adult sample. Multiple regression analysis revealed that behavioral inhibition significantly predicated selfconcealment for women and men. Among men Fun Seeking, a facet of behavioral approach associated with impulsivity, positively predicted self-concealment; and Reward Responsiveness, a facet of behavioral approach associated with movement toward and positive emotion with reward, negatively predicted self-concealment. These results shed light on the relationship of self concealment to behavioral inhibition and behavioral approach and gender differences in self-concealment.
\end{abstract}




\section{Introduction}

Potentially embarrassing or shameful events occur in the lives of many adults: poor academic or work performance, being caught lying to or slandering a friend, taking psychiatric medication, infidelity, acquiring a sexually transmitted disease, infertility, and so forth. Some individuals share these things with friends and family, but for others, the information is shared with no one or only the most minimum number of persons. Why might two people respond differently?

Self-concealment is an individual's tendency to keep negative information about him- or herself secret from others (Larson \& Chastain, 1990). A large body of research has connected the tendency to self-conceal to various negative psychological factors (Kelly \& Archter, 1995; Larson \& Chastain, 1990). Yet, limited research addresses the etiology of self-concealment, or why it emerges in the first place. It is the goal of this research to work on filling in that gap.

This study reviews the literature on self-concealment and outlines the relationship self-concealment has with various physical and psychological variables. A traditional theory, which claims that self-concealment causes negative symptomatology, is called into question. An alternative theory, which proposes that people who self-conceal are unhealthier to begin because they are behaviorally inhibited, is presented. I hypothesize that persons high in self-concealment have higher levels of behavioral inhibition, or are more sensitive to signals of punishment. Furthermore, I propose that behavioral inhibition can better explain 
self-concealment in women than men. These suppositions were based on a body of literature that began with early investigations of secrecy.

Empirical research on secrecy primarily began to emerge in the mid-1980s, amidst investigations that consistently found health benefits from writing about and talking about emotional or traumatic events (e.g., Pennebaker \& Beall, 1986). These findings supported a growing sentiment that withholding thoughts and feelings, especially concerning traumatic events, puts stress on the body that results in negative mental and physical side-effects (Pennebaker \& Susman, 1998).

Individuals' willingness to discuss major upheavals was soon able to be measured by Larson and Chastain's (1990) Self-Concealment Scale (SCS).

\section{Self-Concealment Scale (SCS)}

Larson and Chastain (1990) developed the SCS (see Appendix A) to measure individual levels of self-concealment. Larson and Chastain defined selfconcealment as "a predisposition to actively conceal from others personal information that one perceives as distressing or negative" (p. 440). When selfconcealing, the person consciously withholds information from others (Larson \& Chastain, 1990). The information withheld is typically of an intimate and negative nature. It may include information that is legitimately private (no one else's business) or information to which others believe they are entitled (Larson \& Chastain, 1990; Warren \& Laslett, 1977).

The SCS includes 10 items that measure (a) a self-reported tendency to keep things to oneself, (b) a possession of a personally distressing secret or negative thoughts about oneself that have been shared with few or no other persons, and (c) 
an apprehension about the disclosure of concealed personal information. Larson and Chastain (1990) sought to validate the SCS, measure its predictive validity with physical and psychological symptoms, and distinguish self-concealment from selfdisclosure. This study by Larson and Chastain will next be discussed.

Three hundred six health services professionals and volunteers completed self-report instruments that included the newly developed SCS (Larson \& Chastain, 1990). Factor analyses revealed the SCS to be an internally consistent and largely one-dimensional instrument. Self-concealment was negatively associated with mental and physical health. Specifically, it accounted for unique variance in reports of physical symptoms, depression, and anxiety, even after controlling for social support, size of social network, number and type of traumas, distress associated with a trauma, and individual levels of self-disclosure. Additionally, when scores on the SCS were separated into high and low groups, high self-concealment was associated with more physical and psychological symptoms than low self-concealment. Also, the relationship between self-concealment and trauma distress resulted in an interaction. Participants who reported high self-concealment and high trauma distress had significantly more physical complaints.

Larson and Chastain (1990) conducted the first research on selfconcealment. Subsequent research on self-concealment has supported and elaborated upon the finding that self-concealment is related to physical and psychological complaints. A literature review on self-concealment will next be presented, which begins by clarifying how self-concealment is distinct from selfdisclosure. Then, the relationship self-concealment has with physical complaints, 
distress, social support, self-esteem, and perfectionism is reported. The relationship of self-concealment with attitudes toward counseling and intentions to seek counseling is next addressed. Research on gender, cultural, and age differences in self-concealment is followed by the relationship of self-concealment to splitting tendencies and attachment style. Evidence for conceptualizing self-concealment as a personality dimension is presented. Self-concealment is next contrasted with other personality constructs involving concealment, before presenting an argument for a comparison of self-concealment and behavioral inhibition.

\section{Self-Concealment Literature Review}

\section{Self-disclosure.}

Larson and Chastain (1990) were the first to empirically distinguish selfconcealment from self-disclosure. They claimed that although self-concealment and self-disclosure are related, self-concealment is not just the opposite of selfdisclosure. Self-disclosure involves the revelation of information or what is disclosed. Alternatively, self-concealment involves the concealment of information or what is not disclosed, or more specifically, what is purposefully not disclosed. In other words, just because someone does not self-disclose something does not mean that they are necessarily self-concealing. They simply might not have a lot to say and may not be hiding anything. Larson and Chastain tested the proposition that self-concealment and self-disclosure are not mere opposites.

Larson and Chastain (1990) compared the SCS with the Self-Disclosure Index (SDI; Miller, Berg, \& Archer, 1983), an instrument that asks subjects to estimate the degree to which they disclose information about 10 moderately intimate 
topics (e.g. "what is important to me in life") to particular person(s) in their lives. Scores on the SCS and the SDI were significantly and negatively correlated $(r=-$ .27). Also, self-concealment and not self-disclosure related to physical symptoms, depression, and anxiety.

Self-concealment and self-disclosure have also differed in their predictive power. In adults, self-concealment was found to be more predictive of physical and psychological complaints than self-disclosure (Larson \& Chastain, 1990). Among adolescents, self-concealment from parents predicted physical complaints, depressive mood, and emotional autonomy to a significantly greater and more powerful degree than self-disclosure (Finkenauer, Engels, \& Meeus, 2002). Furthermore, when Finkenauer et al. (2002) controlled for adolescents' levels of self-concealment, the effect of self-disclosure on physical complaints and depression was erased.

Self-concealment and self-disclosure also display different patterns of variation with gender and age, at least among adolescents. Adolescents' levels of self-concealment from their parents did not vary by gender or age. In contrast, selfdisclosure to parents was higher among females and younger adolescents (Finkenauer et al., 2002). However, not all researchers have conceptualized selfconcealment and self-disclosure as truly distinct.

Kahn and Hessling (2001) argued that empirical differences between selfconcealment and self-disclosure result from an instrumentation artifact, or as a result of differences inherent to the SCS and the SDI (the instruments respectively used to measure the two constructs). Kahn and Hessling pointed out that the SDI inquires 
about relatively general information, and the SCS inquires about negative information contributing to distress. They explained that this difference could account for the constructs' empirical distinctiveness. They conceptualized selfconcealment and self-disclosure of distressing information as being on opposite ends of a continuum and developed the Distress Disclosure Index (DDI) to measure this bipolar construct. They found the DDI to be empirically distinct from both the SCS and the SDI. Kawamura and Frost (2004) also used a self-disclosure instrument designed specifically to assess the self-disclosure of problems; their findings supported Larson and Chastain's (1990) original claim regarding the distinctiveness of self-concealment and self-disclosure.

Distinctions between self-concealment and self-disclosure generally emerge, with self-concealment more related to negative symptomatology than the failure to disclose information. Additionally, these constructs are generally considered distinct, rather than opposite manifestations of one construct. (To better conceptualize this nonlinear relationship, self-concealment and self-disclosure can be compared to neuroticism and extraversion: personality factors that similarly show a dichotomous relationship.) Still, the limited instruments with which self-disclosure and self-concealment have been measured warrant further investigation about their relationship.

The SCS is currently the only widely used instrument to measure selfconcealment. This helps to provide consistency in comparing research findings. However, it also restricts the way self-concealment is conceptualized and researched. (These limitations are discussed later.) Thus, the following literature 
review primarily describes self-concealment as conceptualized and measured by the SCS (see Appendix A). The SCS relates to a variety of constructs associated with compromised well-being. These relationships will be examined next, beginning with the association between self-concealment and physical complaints.

\section{Physical symptoms.}

Multiple studies have found significant positive correlations between selfconcealment and reports of physical symptoms. Larson and Chastain (1990) found a significant correlation $(r=.29)$ between self-concealment and complaints of physical symptoms, using a 39-item symptom checklist (Cohen \& Hoberman, 1983). Scores on the Brief Symptom Inventory (BSI; Derogatis, 1993) positively correlated with self-concealment $(r=.36 ; r=.40)$ in college student samples (Kahn, Lamb, Champion, Eberle, \& Schoen, 2002; Kelly \& Yip, 2006). This relationship also emerged with an outpatient clinical sample ( $r=.37$; Kelly, 1998). In a sample of adolescents, Finkenauer et al. (2002) found a relationship between adolescents' self-concealment from their parents and physical symptoms $(r=.33)$ on the Sikkel's Physical Wellness Scale (Sikkel, 1980); both self-concealment and gender (being female) significantly predicted physical symptoms in this study. In addition to complaints of physical symptoms, studies have found positive associations between self-concealment and reports of anxiety, depression, and distress.

\section{Anxiety, depression, and distress.}

Larson and Chastain (1990) found self-concealment positively related to anxiety $(r=.32)$ and depression $(r=.41)$ as measured by subscales of the Typology of Psychic Distress instrument (PSYDIS; Mellinger, Balter, Manheimer, Cisin, \& 
Parry, 1978). Subsequent research supported these seminal findings. Ichiyama et al. (1993) found a positive relationship between self-concealment and anxiety $(r=.30)$ in a college student sample using the Beck Anxiety Inventory (Beck \& Steer, 1990). Also, Kahn and Hessling (2001) found a positive relationship between selfconcealment and anxiety $(r=.30)$ with the Anxiety subscale of the BSI (Derogatis, 1993).

For the relationship between depression and self-concealment, Ichiyama et al. (1993) and Kelly and Archter (1995) found a positive relationship ( $r=.43$ and $r$ $=.50$, respectively) using the Beck Depression Inventory (BDI; Beck \& Steer, 1987) with college student samples. DiBartolo, Li, and Frost (2008) also found a positive relationship between depression and self-concealment $(r=.47)$ with the Depression subscale of the 21-item version of the Depression, Anxiety, and Stress Scale (DASS-D; Lovibond \& Lovibond, 1995a, 1995b). Additionally, Kahn and Hessling (2001) found a positive relationship between self-concealment and depression $(r=$ .46) with the Center for Epidemiological Studies Depression Scale (CES-D; Radloff, 1977). Among adolescents, Finkenauer et al. (2002) and Frijns, Finkenauer, Vermulst, and Engels (2005) found self-concealment positively correlated with depressive mood $(r=.40$ and $r=.43$, respectively), using the Kandel Depression Scale (Kandel \& Davies, 1982); self-concealment and female gender predicted depression in adolescents (Finkenauer et al., 2002). The connection between selfconcealment and depression also emerged when self-concealment measures other than the SCS were used. 
Frost, Parsons, and Nanin (2007) measured concealment in gay men with eight questions that assessed disclosure about sexual orientation. They found that the amount participants worried about others finding out about their sexual orientation was related to reports of depression using the CES-D (Radloff, 1977). A subscale from the Diabetes Coping Scale (Cheng \& Boey, 2000) was also used to measure concealment among elderly Chinese participants with diabetes. The scale included items like "the patient tries to keep others from knowing about the illness" and "keeps feelings to himself/herself and is socially withdrawn." Concealment was significantly associated with $(r=.62)$ and was the most significant predictor (above social support and coping style) of depressive symptoms.

Self-concealment has also been associated with multiple measures of distress. Lopez, Mitchell, and Gormley (2002) found that self-concealment positively correlated with distress as measured by the Hopkins Symptom Checklist (HSCL; Derogatis, Lipman, Rickels, Uhlenhuth, \& Covi, 1974). Cepeda-Benito and Short (1998) and Kawamura and Frost (2004) similarly found positive associations ( $r=.44$ and $r=.52$, respectively) between distress and self-concealment with the abbreviated HSCL-21 (Green, Walkey, McCormick, \& Taylor, 1998). Liao, Rounds, and Klein (2005) measured distress with an adapted version of the Personal Problems Inventory (PII; Gim, Atkinson, \& Whiteley, 1990), a measure of common problems experienced by college students, and found self-concealment significantly related to distress for Caucasian $(r=.49)$ and Asian/Asian American $(r=.33)$ college students. Similar results with the PPI were found with a general college student sample ( $r=.43$; Lopez et al., 2002). Also, Wismeijer and van Assen (2008) 
found self-concealment negatively associated with reports of subjective well-being $(r=.20$ and $r=.24)$ as measured by a Dutch translation of the World Health Organization-Five Well-being Index (WHO-5; Bech, 1998). Research has also connected self-concealment to weaker social supports.

\section{Social support.}

Larson and Chastain (1990) found that self-concealment was negatively correlated to the number of persons (not including relatives) with whom participants reported being close $(r=-.33)$ and the degree of support that participants reported receiving from persons (excluding their spouse) in their life $(r=-.27)$. Kelly and Archter (1995) and Kelly and Yip (2006) found scores on the Social Provisions

Scale (SPS, overall scale; Cutrona \& Russell, 1987), a measure of social support system strength, to negatively relate to self-concealment $(r=-.45$ and $r=-.35$, respectively). Cepeda-Benito and Short (1998) also found a negative relationship between social support and self-concealment $(r=-.28)$ using the Wilcox Social Support Network Survey (WSSNS; Reis, 1988; Wilcox, 1981). Liao et al. (2005) found a significant negative relationship between self-concealment and perceived social support for Caucasian $(r=-.48)$ and Asian/Asian American $(r=-.41)$ college students using the Interpersonal Support Evaluation List (ISEL; Cohen, Mermelstein, Kamarack, \& Hoberman, 1985). Among Korean college students, Yoo, Goh, and Yoon (2005) found that self-concealment negatively related to social network orientation, or the degree one believes his or her social support system will be useful in problem situations, as measured by the Network Orientation Scale 
(NOS; Vaux, 1985). In addition to social support, self-concealment relates inversely to self-esteem.

\section{Self-esteem.}

Self-concealment negatively correlates with self-esteem. Using the Rosenberg Self-Esteem Scale (Rosenberg, 1979), Ichiyama et al. (1993) found a negative relationship between self-concealment and self-esteem $(r=-.41)$ in a college student sample. Likewise, a negative relationship between self-esteem and self-concealment $(r=-.37)$ emerged among adolescents when examining their degree of self-concealment from their parents (Frijns et al., 2005). DiBartolo et al. (2008) found self-concealment to positively relate to a factor labeled Contingent Self-Worth, which was comprised of scores from the Contingent Self-Worth Scale (CSWS; Crocker, Luhtanen, Cooper, \& Bouvrette, 2003) and the Perfectionistic Self-Worth Scale (PSWS; DiBartolo, Frost, Chang, LaSota, \& Grills, 2004). In other words, self-concealment positively associated with the degree to which one's self-esteem is contingent on sources outside of the self, such as performance and achievement (DiBartolo et al., 2008). The connection between self-concealment and attention to achievement may relate to the link between self-concealment and perfectionism.

\section{Perfectionism.}

Kawamura and Frost (2004) studied the relationship between selfconcealment and perfectionism. Perfectionism was measured using the Multidimensional Perfectionism Scale (MPS), which includes four Maladaptive Perfectionism (MAL-PER) subscales and one Personal Standards subscale (Frost, 
Marten, Lahart, \& Rosenblate, 1990). The MAL-PERF subscales measure maladaptive aspects of perfectionism: (a) negatively reacting to mistakes, (b) doubting one's ability to complete tasks, (c) perceiving parents as overly critical, and (d) perceiving one's parents as having established extremely high standards. The Personal Standards subscale measures positive characteristics of perfectionism, including setting high standards for oneself.

Kawamura and Frost (2004) found self-concealment and perfectionism significantly correlated for women $(r=.61 ; n=116)$, but not men $(r=.08 ; n=29)$. For women, Maladaptive Perfectionism, not Personal Standards, significantly and positively correlated with self-concealment and psychological distress, as measured by the HSC-21 (Green et al., 1998). Path analytic techniques revealed that selfconcealment mediated the relationship between the perfectionism and distress. In other words, perfectionism no longer correlated with distress when controlling for self-concealment.

DiBartolo et al. (2008) similarly found the Maladaptive Perfectionism subscales associated with self-concealment $(r=.46)$ in an all-women college student sample. Like Kawamura and Frost (2004), DiBartolo et al. found Personal Standards not significantly related to self-concealment. Also, self-concealment was the full and only mediator for the negative relationship between Maladaptive Perfectionism and positive affectivity, as measured by the Positive Affect Subscale of the Positive and Negative Affect Scale, Trait Version (PANAS-PA; Watson, Clark, \& Tellegen, 1988). Self-concealment additionally associated with a Contingent Self-Worth factor, comprised of two instruments that measure the degree self-esteem is based 
on accomplishment, performance, and other external sources (DiBartolo et al., 2008). Results indicated that self-concealment and Contingent Self-Worth partially mediated the relationship between Maladaptive Perfectionism and indices of depression and fear of negative evaluation and fully mediated the relationship between Maladaptive Perfectionism and scores on the Eating Disorder Diagnostic Scale (EDDS; Stice, Telch, \& Rizvi, 2000).

Kawamura and Frost (2004) examined whether persons with perfectionistic beliefs disclosed different kinds of personal information to different people using the College Issues Questionnaire (CIQ). Developed for the study, the CIQ presents participants with a range of specific problems for which college students may seek counseling (e.g., loneliness, conflicts with parents). Participants rate on 4-point Likert-type scales their willingness to disclose 24 different issues to a friend, family member, and counselor/therapist. Results revealed that a willingness to discuss issues with family and with friends was negatively related to self-concealment $(r=$ .35 and $r=-.37$, respectively) and maladaptive perfectionism $(r=-.43$ and $r=-.38$, respectively). However, a willingness to discuss these issues with a therapist was not related to self-concealment $(r=-.08)$ or maladaptive perfectionism $(r=-.02)$. Kawamura and Frost concluded that persons with perfectionistic beliefs may perceive their struggles as indicative of personal flaws that should be kept hidden and, accordingly, tend to withhold personally distressing information from friends and family. Interestingly, self-concealment and maladaptive perfectionism were not related to their willingness to disclose to a counselor (Kawamura \& Frost, 2004). 
The relationship between self-concealment and college students' seeking of psychological services will next be examined.

\section{Attitudes toward seeking counseling services.}

Several researchers examined the relationship between self-concealment and attitudes toward seeking counseling services. Using the Fischer-Turner Attitudes Toward Seeking Professional Psychological Help Scale (Fischer \& Turner, 1970), Kelly and Archter (1995) and Cepeda-Benito and Short (1998) found a negative relationship between self-concealment and attitudes toward seeking counseling $(r=$ -.27 and $r=-.20$, respectively). In other words, higher levels of self-concealment were associated with more negative views of counseling. Liao et al. (2005) found similar results among Caucasian college students $(r=-.24)$ and an even stronger relationship among Asian and Asian American college students $(r=-.42)$. A negative relationship between self-concealment and attitudes toward counseling was also found with a sample of counselors-in-training (Leech, 2007). Among African American college students a relationship between self-concealment and attitudes toward counseling did not emerge ( $r=-.06$; Wallace \& Constantine, 2005). This deviates from most findings that point to a positive relationship between selfconcealment and negative attitudes toward counseling.

Kelly and Archter (1995) hypothesized that self-concealers have negative attitudes toward counseling because they fear revealing highly personal information. Kelly and Archter (Study 2) presented college students with a written description of counseling that either mentioned or did not mention the need for clients to selfdisclose in counseling. Students then wrote words to describe their perceptions of 
counseling. The valence, or degree of attraction or aversion, of their descriptors was analyzed. Results revealed that high self-concealers had significantly less favorable descriptors of counseling than low self-concealers, but this was only among those whose scenario mentioned self-disclosure. Kelly and Archter's hypothesis is also supported by Cepeda-Benito and Short (1998), who found a positive relationship between self-concealment and fears of psychotherapy $(r=.33)$, as measured by the Thoughts about Psychotherapy Survey (TAPS; Kushner \& Sher, 1989). Although self-concealment generally relates to negative attitudes toward counseling, it, somewhat paradoxically, also relates to intentions to seek counseling.

\section{Intentions to seek counseling services.}

Somewhat contradictory to the positive relationship between selfconcealment and negative attitudes toward counseling (e.g., Cepeda-Benito \& Short, 1998), some self-concealers are more likely to report seeking counseling. Kelly and Archter (1995) found a positive correlation between self-concealment and college students' intentions to seek counseling $(r=.14)$ using the Intentions to Seek Counseling Inventory (ISCI; Cash, Begley, McCown, \& Weise, 1975). Furthermore, Kelly and Archter found that significantly more high self-concealers (57\%) than low self-concealers $(37 \%)$ reported having seen a counselor.

In contrast, Cepeda-Benito and Short (1998) did not find a significant relationship between self-concealment and intentions to seek counseling $(r=.06)$ and did not find a significant difference in the percentage of high and low selfconcealers who reported having seen a counselor (although the numbers were in the same direction as in Kelly and Archter, 1995). Liao et al. (2005) similarly did not 
find a significant relationship between self-concealment and intentions to seek counseling among Caucasian $(r=.06)$ and Asian/Asian American $(r=.05)$ college students. However, Cepeda-Benito and Short found that significantly more high self-concealers $(37 \%)$ than low self-concealers $(12 \%)$ reported having needed but not having sought professional psychological services. Examination also revealed an interaction between self-concealment and social support (Cepeda-Benito \& Short, 1998). Persons with high levels of self-concealment, regardless of their level of social support, anticipated needing to seek counseling. Otherwise, persons with high levels of social support were less likely to anticipate needing to seek counseling (Cepeda-Benito \& Short, 1998).

Cramer (1999) used path analytic techniques to reexamine the conflicting data between Kelly and Archter (1995) and Cepeda-Benito and Short (1998) regarding self-concealment and intentions to seek counseling. He concluded that an indirect relationship between self-concealment and help-seeking behaviors through distress best accounted for their data. In other words, individuals high in selfconcealment had increased levels of distress that, if sufficient, boosted their likelihood of seeking counseling. Also, through a comparison of standardized path loadings, self-concealment was found more strongly related to distress than attitudes toward counseling. Cramer concluded that self-concealers' high levels of distress make them more likely to seek counseling, even though their negative attitudes toward counseling may contribute to hesitancy in seeking help. Cramer's model also held for a sample of counselors-in-training (Leech, 2007). Liao et al. (2005) tested Cramer's model with an Asian and Asian American college student sample and a 
sample of Caucasian college students. The results generally matched what Cramer's model predicted. However, structural invariance suggested differences in the models for Caucasian and Asian/Asian American samples (Liao et al., 2005). Studies focusing on self-concealment with specific cultural and ethnic groups, including more findings from Liao et al. will next be discussed.

\section{Culture.}

Self-concealment has been associated with anxiety, weaker social supports, and distress among college students in Japan and among Asian and Asian American college students in the United States (Liao et al., 2005; Omori, 2007). Among Japanese college students, self-concealment related to insecure attachment and interpersonal distance, or the distance persons felt comfortable physically interacting with others (Yukawa, Tokuda, \& Sato, 2007). For college students in Japan and Asian and Asian American college students in the United States, selfconcealment negatively related to attitudes toward counseling (Liao et al., 2005; Omori, 2007). Furthermore, the relationship between self-concealment and attitudes toward counseling was stronger for Asian and Asian American students than for Caucasian students (Liao et al., 2005). The fit of the path analytic model purposed by Cramer (1999), where high levels of distress make self-concealers more likely to seek counseling, significantly improved for Asian and Asian American students when adherence to Asian values was included (Liao et al., 2005). Liao et al. (2005) suggested that self-concealment may be related to the value of avoiding shame or loss of face in Asian culture. Self-concealment with other cultural groups has also been examined. 
Constantine, Okazaki, and Utsey (2004) examined self-concealment among African, Latin American, and Asian international students in the United States. Among the international students, self-concealment positively related to depression $(r=.53)$, as measured by the CES-D (Radloff, 1977), and acculturative stress $(r=$ .73), as measured by the Acculturative Stress Scale for International Students (ASSIS; Sandhu \& Asrabadi, 1994). Self-concealment also negatively related to social self-efficacy $(r=-.22)$, as measured by Social Self-efficacy Subscale (SSES) of the Self-Efficacy Scale (Sherer \& Adams, 1983). African international students, when compared to Asian and Latin American international students, reported significantly higher levels of self-concealment, in addition to higher levels of acculturative stress and depression (Constantine et al., 2004). Constantine and colleagues (Constantine et al., 2004; Wallace \& Constantine, 2005) suggested that Africentric characteristics, such as high collectivism, may lead to self-concealment, in that self-concealment may preserve interpersonal harmony through the inhibition of personal problems.

Wallace and Constantine (2005) found that among African American college students self-concealment positively correlated $(r=.44)$ with scores on the Africentrism Scale (AS), a self-report measure of Africentric values, such as unity and faith (Grills \& Longshore, 1996). Among the college students, self-concealment also correlated with perceived stigma toward counseling $(r=.21)$, as measured by the Stigma Scale for Receiving Psychological Help (SSHRPH; Komiya, Good, \& Sherrod, 2000). Self-concealment did not relate to negative attitudes toward counseling $(r=-.06)$, which differs from findings with other samples (e.g., Kelly \& 
Archter, 1995). More research on self-concealment with African Americans is important, especially to understand whether such differences were sample specific or reflect cultural differences. It is also important to consider how racism contributes to or interacts with cultural values to influence or increase selfconcealment. Prejudice and discrimination may similarly relate to self-concealment for gay men and women.

Frost et al. (2007) examined concealment of sexual orientation among gay men. The authors measured participants' disclosure of their sexual orientation and concern about their sexual orientation being revealed to others with eight questions. The authors found that concealment of sexual orientation was associated with perceptions of negative societal attitudes toward gays and personalized stigma, or the perception of social consequences related to being gay. Concealment was also related to symptoms of depression, and concealment partially mediated the relationship between personalized stigma and depressive symptoms among the gay men (Frost et al., 2007).

Potoczniak, Aldea, and DeBlacre (2007) found that among gay men, lesbians, and bisexual adults, SCS scores negatively related to social support $(r=-$ .41), as measured by the Multidimensional Scale of Perceived Social Support (MSPSS; Zimet, Dahlem, Zimet \& Farley, 1988) and positively related to social anxiety $(r=.36)$, as measured by the Social Anxiety subscale of the SelfConsciousness Scale-Revised (Scheier \& Carver, 1985). Social support significantly mediated the relationship between social anxiety and self-concealment. The authors, interested in sexual minority identity development, also found self-concealment 
negatively related to identity commitment, and social support mediated the relationship between social anxiety and ego identity. Potoczniak et al. also found men to have significantly higher levels of self-concealment than women. The authors concluded that the higher degree of stigma for gay men, in comparison to women, likely led to increased self-concealment among this population of men. Moreover, social support may be a particularly crucial component of gay men and women's well-being, in that it affected levels of identity development and selfconcealment. Potoczniak et al. also stressed that although the SCS does not specifically assess concealment of sexual identity, self-concealment is especially relevant for the gay community because concealment of sexual orientation often necessitates or leads to concealment of other information, such as with whom time is spent.

How self-concealment differs for individuals from various cultural, ethnic, socioeconomic, and differentially privileged groups should be an important component of future research. Differences could be influenced by what is considered taboo both within that group and by others outside the group. Still, individual differences should also be taken into account when considering cultural contributions to self-concealment. Sitting somewhere at a crossroads between culture and individual differences is gender. The relationship between gender and self-concealment will next be discussed.

\section{Gender.}

Self-concealment research does not generally show significant differences between males and females' mean scores on the SCS (Constantine et al., 2004; 
Ichiyama et al., 1993; Kawamura \& Frost, 2004; Kelly \& Archter, 1995; Omori, 2007, Yukawa et al., 2007). These results support original findings by Larson and Chastain (1990), who did not find a significant difference in levels of selfconcealment for males and females. However, at least two studies found higher levels of self-concealment in men.

Cramer and Barry (1999) found males had significantly higher levels of selfconcealment than females. Males' self-concealment scores in Cramer and Barry were significantly higher than those found by Larson and Chastain (1990; albeit a small difference in magnitude). Cramer and Barry noted the small number of males $(n=29)$ and the unrepresentativeness (primarily helping-professionals) of the Larson and Chastain sample. Men also had higher levels of self-concealment in a sample of lesbians, gay men, and bisexual adults (Potoczniak et al., 2007). The authors attributed this finding to the higher degree of stigma for gay men, in comparison to women, which could lead to higher levels of self-concealment. Thus, although some studies have found higher self-concealment scores among men, most research points to nonsignificant differences in men and women's average selfconcealment scores. Still, the relationship between self-concealment and some variables has been shown to vary by gender.

Ichiyama and colleagues (1993) accounted for more variance in selfconcealment among females than males. Ichiyama et al. found that for females, depression, self-esteem, anxiety, and shyness (all four of their predictor variables) significantly contributed to levels of self-concealment (with shyness and self-esteem having the greatest contribution). However, among males, depression was the only 
variable to significantly predict self-concealment (self-esteem approached significance). Also, Kawamura and Frost (2004) found that the correlation between self-concealment and perfectionism was much higher for women $(r=.61)$ than for $\operatorname{men}(r=.08)$.

Significant gender differences in mean self-concealment scores did not emerge when examining adolescents' levels of self-concealment from their parents (Finkenauer et al., 2002; Frijns et al., 2005). However, Frijns et al. (2005) did find gender differences in the relationship between self-concealment and delinquency (self-report). Self-concealment (from parents) was more strongly related to delinquency in males than females (although this gender difference did not emerge six months later). In sum, although mean self-concealment scores generally do not significantly vary by gender, gender differences have emerged when examining the relationship of self-concealment to other constructs. Such differences could be used to support the premise that different variables contribute to self-concealment in females and males. This idea will be returned to later in this research. Selfconcealment in adolescence will next be discussed.

\section{Adolescents.}

Researchers questioned whether or not the association between selfconcealment and negative symptomatology holds for adolescents, given the supposition that self-concealment could play an important, positive role in adolescent development (Finkenauer et al., 2002; Frijns et al., 2005). For this research, the SCS and the SDI were adapted to respectively address adolescents' self-concealment from and self-disclosure to their parents (Finkenauer et al., 2002; 
Frijns et al., 2005). For example, the SCS item "My secrets are too embarrassing to share with others" was changed to "My secrets are too embarrassing to share with my parents."

Results from two groups of adolescents in the Netherlands, ages 12 to 13 and 16 to 18 , revealed that, as with adults, self-concealment negatively related to and significantly predicted physical complaints and depressive mood (Finkenauer et al., 2002). Furthermore, the effects of self-concealment on these measures were stronger than the effects of self-disclosure. In other words, the amount of information adolescents intentionally kept from their parents was negatively and more strongly related to adolescent well-being than the amount they disclosed to them (Finkenauer et al., 2002).

Finkenauer et al. (2002) speculated that self-concealment in adolescence could be advantageous by assisting with the developmental process of individuation. They predicted that self-concealment would be more strongly associated with negative symptomatology for younger than older adolescents, since they would be less individuated and feel more tormented about keeping secrets from their parents. However, this hypothesis was not supported. Self-concealment was not associated with more negative symptoms among younger adolescents.

Finkenauer et al. (2002) also hypothesized a positive relationship between self-concealment and emotional autonomy. This hypothesis was supported; results revealed that self-concealment positively related to and significantly predicted emotional autonomy. Also, the effect of self-concealment on emotional autonomy was stronger than that of self-disclosure and satisfaction with parents. Finkenauer et 
al. framed increased emotional autonomy as an advantage of self-concealment and posited that the disadvantages associated with self-concealment found in their study (physical complaints and depressive mood) were likely natural consequences of adolescent development, which eventually resulted in the greater good of individuation. However, other researchers have conceptualized emotional autonomy, particularly as measured by Steinberg and Silverberg's Emotional Autonomy Scale (1986) as used by the authors, as a measure of detachment from parents rather than of positive individuation (Smetana, Metzger, Gettman, \& Campione-Barr, 2006). Further research sought to clarify whether self-concealment in adolescence could be understood as advantageous.

Frijns et al. (2005) predicted that self-concealment from parents would positively correlate with self-control, given the positive relationship between selfconcealment and emotional autonomy and the suggested positive relationship between self-concealment and individuation (Finkenauer et al., 2002). Using a longitudinal design, researchers presented questionnaire packets to young adolescents in the Netherlands at two data collections, six months apart (Frijns et al., 2005). In total, data was received from 1173 adolescents, ages 10 to 14 . The SCS was administered only at Time 1 . Dependent measures were collected at Time 1 and Time 2. Results revealed that their hypothesis was not supported; self-concealment showed a significant negative correlation with self-control. Furthermore, adolescents' self-concealment was associated with negative self-esteem, depressive mood, and stress at Time 1 and Time 2. Correlations at Time 2 were lower than at Time 1, but remained significant. The authors controlled for the variables 
communication with parents, trust in parents, and parental supportiveness. These variables had modest, but significantly negative correlations with self-concealment. They also had minimal impact on the relationship of self-concealment with selfesteem, depressive mood, and stress (Frijns et al., 2005).

Frijns et al. (2005) also examined the relationship between self-concealment and behavioral problems, specifically self-reports of aggression and delinquency. Self-concealment from parents was associated with aggressive behavior and delinquency at Time 1 and Time 2. However, when parental variables were controlled for, the relationship between self-concealment and delinquency was no longer significant at Time 2. Also, self-concealment had a stronger association with delinquency for males than females at Time 1, but this difference was not found at Time 2 (Frijns et al., 2005).

Although it has been speculated that self-concealment may be advantageous in adolescent development, research does not seem to support this hypothesis. In adolescents self-concealment was associated with similar negative symptomatology as found in adults, including physical complaints, depressive mood, negative selfesteem, and stress (Finkenauer et al., 2002; Frijns et al., 2005). Additionally, selfconcealment was negatively related to self-control (Frijns et al., 2005) and positively related to emotional autonomy (Finkenauer et al., 2002); both believed to be associated with poor well-being (Smetana et al., 2006). The above research supports the association between self-concealment and indicators of negative wellbeing prior to adulthood. It further gives way to speculation regarding a connection 
between self-concealment and characteristics emergent early in life, such as splitting tendencies and attachment styles.

\section{Early development.}

Splitting is presumed to develop in early infancy. It has been characterized as a tendency to conceptualize the self and others as either all good or all bad (Kernberg, 1976). Friends, family, and the self are often seen in black or white terms. This occurs when persons have difficulty integrating images of the self and others as both good and bad. While this defense mechanism can help persons make sense of the world and protect them from unpleasant emotion, splitting has been associated with psychological problems, including borderline and narcissistic personality disorders (Gould, Prentice, \& Ainslie, 1996; Kernberg, 1976). Lopez examined the relationship between splitting and self-concealment.

The Self-Splitting subscale of the Splitting Index (SI) measures fragmented views of the self (Gould et al., 1996). Using the SI, Lopez (Lopez, 2001; Lopez et al., 2002) found self-splitting positively correlated with self-concealment $(r=.45$ and $r=.47$, respectively). A similar association $(r=.31)$ was found between the Other-Splitting subscale of the SI and self-concealment (Lopez, 2001). These results suggest that self-concealment is associated with fragmented or inconsistent views of oneself and others, which, like attachment style, presumably develops early in childhood.

Self-concealment also relates to insecure attachment. Using the Experiences in Close Relationships (ECR; Brennan, Clark, \& Shaver, 1998) instrument, Lopez (2001) found self-concealment correlated negatively with secure attachment $(r=$ - 
.40) in a college student sample (Lopez, 2001). Furthermore, Lopez (Lopez, 2001; Lopez et al., 2002) found self-concealment correlated positively with anxious ( $r=$ $.31, r=.33)$ and avoidant $(r=.39, r=.42)$ attachment styles. Yukawa et al. (2007) found similar results among Japanese college students using the Japanese SelfConcealment Scale (Kawano, 2000); self-concealment correlated with anxious $(r=$ $.47)$ and avoidant $(r=.43)$ attachment styles.

Lopez (2001) suggested that anxiously attached individuals self-conceal to reduce the risk of social rejection and to maintain interpersonal closeness. Persons with an avoidant attachment style, on the other hand, may self-conceal to cope with their discomfort with intimacy and to maintain an air of self-sufficiency (Lopez, 2001). Lopez et al. (2002) viewed insecurely attached individuals as having inadequate self-organizational processes, with self-concealment and splitting, respectively, contributing to insincere self-presentations and disorganized beliefs about the self and both contributing to distress. In partial support of their hypothesis, self-concealment and self-splitting mediated the relationship between anxious (but not avoidant) attachment style and distress (Lopez et al., 2002). Also, selfconcealment significantly predicted self-splitting (but not other-splitting). Together, these results suggest that self-concealment shares important features with anxious attachment style and self-splitting, which deserves further investigation. These findings also highlight the importance of considering early-developing personality characteristics in the etiology and perpetuation of self-concealment.

Research has connected high levels of self-concealment to negative symptomatology, including physical complaints, anxiety, depression, distress, low 
social support, low self-esteem, perfectionism, and insecure attachment (e.g., Ichiyama et al., 1993; Kawamura \& Frost, 2004; Larson \& Chastain, 1990; Lopez, 2001). These links appear present in adults, adolescents, males, females, and persons of various cultural backgrounds (e.g., Finkenauer et al., 2002; Larson \& Chastain, 1990; Omori, 2007). Self-concealment has also been related to negative attitudes toward counseling and an increased likelihood to seek counseling due to the relationship between self-concealment and high levels of distress (Cramer, 1999). Given that self-concealment has been associated with so many indictors of negative well-being, it seems important to better understand why this relationship exists. Early research speculated that a casual relationship existed between selfconcealment and negative symptomatology, in that concealment leads to physical and psychological health problems (Larson \& Chastain, 1990). However, newer research challenges this assumption (Kelly \& Yip, 2006).

\section{Theories to Account for These Findings}

Larson and Chastain (1990) conceptualized that the relationship between secrecy and mental and physical health problems emerged as a function of the physiological work required when withholding information (Pennebaker \& O'Heeron, 1984). This explanation, also known as inhibition theory, claims that keeping a secret is a stressful act that taxes one's resources. Inhibition theory posits that keeping something secret necessitates active restraint, and this restraint contributes to stress on the mind and body (e.g., Pennebaker \& O'Heeron, 1984; Pennebaker \& Susman, 1988). 
Inhibition theory was used to explain emerging research in the 1980s that found physical and psychological benefits from the writing and/or disclosure of traumatic events (Pennebaker \& Beall, 1986). It was theorized that after writing or talking about the event, the information and emotion is no longer being restrained, which decreases negative symptomatology. However, after over two decades of research, inhibition theory has received mixed results (Pennebaker \& Chung, 2007). Empirical research suggests that benefits emerge from disclosure regardless of whether or not the event has been previously kept secret (e.g., Pennebaker \& O'Heeron, 1984). Accordingly, inhibition theory is no longer the central theory used to explain positive effects from writing and talking about traumatic events (Pennebaker \& Chung, 2007).

Self-concealment researchers have also speculated that self-concealment is related to negative side effects because self-concealers miss out on social feedback, such as normalization and support that comes along with self-disclosure (Ichiyama et al., 1993; Larson \& Chastain, 1990). However, the benefits of disclosure seem to surface independent of social feedback. Health benefits were found when participants spoke into an audio recorder, wrote on a magic pad (where the writing disappears with the lifting of a cover sheet), and wrote with their finger (as if their finger was a pen) (Pennebaker \& Chung, 2007). Furthermore, self-concealment relates to negative symptomatology even when controlling for social support (Kelly \& Yip, 2006).

Pennebaker and Chung (2007), in a summary and integration of previous research on health and expressive writing, explained that the physical and 
psychological benefits that emerge subsequent to disclosure result from the process of giving words to the feelings and contents surrounding a traumatic event. Attaching language to experience enables the transfer of visceral emotions to a cognitive framework. Within that cognitive framework an individual can make sense of his or her experience and reaction to it. This further enables the individual to assimilate the experience into his or her worldview. The event then consumes less cognitive space and energy, and negative effects on health are diminished (Pennebaker \& Chung, 2007). This framework suggests that self-concealers miss out on the benefits afforded to those who talk or write about their problems (Kelly \& Yip, 2006). However, it does not infer that self-concealment, in and of itself, is harmful (Kelly, 2002). Kelly and Yip (2006) explained that no direct evidence exists to indicate that secret-keeping is harmful and further proposed that secret-keeping can have psychological benefits and social rewards (Kelly, 2002).

Kelly and Yip (2006) posited that self-concealment, as assessed by the SCS, is more reflective of a personality constellation than secret-keeping, per se. They proposed that only self-concealment, and not the act of keeping a secret, is associated with negative symptomatology. It has also been noted that in many contexts keeping a secret can be beneficial, such as when it serves to maintain one's reputation or an important relationship (Cameron, Holmes, \& Vorauer, 2009; Kelly \& Yip, 2006). To test their hypothesis, Kelly and Yip performed a study with two data collections 9 weeks apart. The SCS was used to measure self-concealment and a forced choice option ("YES, I have a major secret at this time" or "NO, I do not have a major secret at this time") was used to measure the act of keeping a secret. 
The Global Severity Index of the Brief Symptom Inventory (BSI; Derogatis, 1993) was used to measure negative symptomatology. The Social Provisions Scale (SPS; Cutrona \& Russell, 1987) measured social support.

The 86 participants who reported having a secret $(71 \%$ of the total participants) had significantly higher self-concealment scores (Kelly \& Yip, 2006). However, keeping a secret and self-concealment had different predictive effects. Self-concealment scores at Time 1 predicted higher symptomatology scores at Time 2. However, secret-keeping (and social support) at Time 1 was related to lower symptomatology scores at Time 2 . Kelly and Yip (2006) also included social desirability, the perceived stress surrounding keeping the secret, and how long the secret had been kept in the regression analyses. Each was not found to significantly predict symptoms; only self-concealment predicted higher symptomatology. These findings support results from Kelly (1998), which showed that clients who reported having kept a secret from their therapist also reported less symptomatology. However, Kelly and Yip cautioned that it should not be concluded that selfconcealment led to the negative symptoms and performed additional analyses to punctuate their belief.

In the second part of their study, Kelly and Yip (2006) reran their analyses, but controlled for initial levels of symptomatology. After controlling for symptomatology scores at Time 1 , the predictive relationships between secrecy and symptomatology at Time 2 were erased. Self-concealment scores no longer predicted higher symptomatology scores, and secret-keeping no longer predicted lower symptomatology scores. Kelly and Yip explained that since self-concealment 
scores were significantly related to symptomatology scores at Time 1, it should be expected that they would be related at Time 2, especially given that it was a nonclinical sample, whose scores do not generally vary over time. Kelly and Yip explained that they expected this finding, which they reported to demonstrate the fallibility of suggesting causality with correlation-based research, even with a longitudinal design.

Kelly and Yip (2006) highlighted two important points. First, one should be extremely cautious when attributing causality from analyses within the correlational family. The relationship between self-concealment and negative symptomatology, even at a later time, should not imply that one caused the other. Second, selfconcealment is not identical to the act of keeping a secret. Consequently, selfconcealment and keeping a secret should not be used interchangeably, especially given that the former is related to negative and the latter positive reports of wellbeing. Self-concealment, as measured by the SCS, involves not only concealment, but also apprehension about the concealed information and its potential revelation. Therefore, understanding self-concealment may involve examining personality constructs involving concealment and negative affectivity. Several personality styles involving concealment will next be presented and their potential relationship with self-concealment explored.

\section{Personality Constructs}

\section{Repressive-defensive personality style.}

The repressive-defensive personality style stems from the defense mechanism repression and describes a non-conscious tendency to avoid consciously 
experiencing negative feelings or thoughts (Garssen, 2007; King, Emmons, \& Woodley, 1992; Weinberger, 1990). Repression can be compared to suppression, which shows to be empirically distinct from repression (Garssen, 2007; Giese-Davis \& Spiegel, 2001; King et al., 1992). With suppression, the individual is conscious of negative emotion, but withholds its expression until a supposedly more socially appropriate time (Garssen, 2007; Weinberger, 1990). In contrast, repressors are committed to demonstrating to both themselves and others that they are not at all inclined to experience negative emotion (Weinberger, 1990; Weinberger, Schwartz, \& Davidson, 1979). However, negative affect ultimately arises in repressors when their belief that they do not experience negative emotion, central to their selfconcepts, clashes with the reality of their behavior (Higgins, 1987). Repressors may use multiple methods to evade awareness of their negative emotion, including misinterpreting their emotional experiences (Weinberger, 1990). For example, repressors report low levels of anxiety, even when physiological measures indicate otherwise (Weinberger, 1990; Weinberger \& Schwartz, 1990; Weinberger et al., 1979).

The repressive-defensive personality style has been associated with less selfdisclosure. In an experimental interview, repressors revealed less personal information and were less accurate in estimating the amount they disclosed (Doster, 1975). Still, repressors should not automatically be regarded as self-concealers. For a person to score high on the SCS, the person must be aware of (and acknowledge) keeping a secret and his or her anxiety surrounding it. Given the unconscious nature of repression, together with its negative association with self-reported distress, 
measures of self-concealment and repression would not be expected to be positively related. In support, Ritz and Dahme (1996) found that repressors had the lowest levels of self-concealment on a German version of the SCS (Ritz \& Dahme, 1994). In other words, while repressors may conceal personal information, they may or may not be aware of their concealment and are generally unaware of any negative affect surrounding it. In contrast, self-concealers are cognizant of their concealing behavior and their surrounding negative affect.

Weinberger et al. (1979) categorized repressors as self-reporting low trait anxiety and high social desirability. [Weinberger and Schwartz (1990) later adapted this classification by changing high social desirability to high restraint.] The positive relationship between repression and high social desirability seems reflective of repressors' beliefs that they do, indeed, meet high personal and moral standards (Millham \& Kellogg, 1980). Hence, one might speculate that self-concealers, like repressors, show high levels of social desirability. However the relationship between self-concealment and social desirability remains unclear.

Garssen (2007) suggested that self-concealers, along with habitual suppressors, may fall into a category described by Weinberger and colleagues (Weinberger \& Schwartz, 1990; Weinberger et al. 1979) as high on measures of both social desirability (or restraint) and distress. This group, also referred to as Oversocialized, is associated with physical and psychological problems (Weinberger \& Schwartz, 1990). However, Weinberger and colleagues did not specify the type of social desirability associated with repressors or this anxious defensive group. 
Social desirability had been divided into self-deception and other-deception (or impression management), with the former reflecting unconscious and the latter purposeful self-favoring biases (Paulhus, 1984; Sackeim \& Gur, 1978). However, newer research suggests the unconscious versus conscious distinction is not as meaningful as once believed (Paulhus, 1984; Paulhus, 2002; Paulhus \& John, 1998). Instead, the two social desirability factors, Alpha and Gamma (Block, 1965; Wiggins, 1964), appear to reflect two different types of motivations, the need for affiliation or approval and the need for power, respectively (Paulhus, 2002; Paulhus \& John, 1998). The former values relationships and benefiting society as a whole, which may dispose one to exaggerate or overestimate characteristics related to being nice or a good citizen, also known as a moralistic bias. The latter values personal achievement and may lead to an egoistic bias, or the tendency to embellish or overestimate personal qualities related to intellect and social status (Paulhus \& John, 1998). While some social desirability instruments clearly load on either the Alpha or the Gamma factor, the Marlowe-Crowne Social Desirability Scale (MCSDS; Crowne, 1979) loads on both factors (Paulhus, 1984). The MCSDS has been compared to self-concealment, and mixed results have emerged.

Negative (Kahn \& Hessling, 2001; Kahn et al., 2002), positive (Lopez, 2001), and nonsignificant (Kelly, 1998; King et al., 1992) relationships have emerged between the MCSDS and the SCS. Additionally, Ritz and Dahme (1996) found a negative correlation between self-concealment and the MCSDS for German men, but not women. Furthermore, Kelly and Yip (2006) found scores on the short form of the MCSDS (MC Form C; Reynolds, 1982) did not predict symptoms on the BSI 
(Derogatis, 1993), and the relationship between self-concealment, secret-keeping, and symptomatology did not change when social desirability scores were included in a regression. If self-concealment is more related to one social desirability factor over the other, use of the MCSDS may obscure this relationship given that it loads on both factors. Still, it could be speculated that self-concealment relates more to the Gamma factor, also conceptualized as a moralistic bias (Paulhus, 1984; Paulhus \& John, 1998).

Paulhus and John (1998) suggested that Gamma may serve a self-protective function, where disapproval is avoided by conforming to social norms, which may be similar to the role of self-concealment. In support, the Gamma factor is marked by the personality factors Agreeableness and Conscientiousness. Also, persons who score high on the Gamma factor, report more psychopathology and negative affect and are more likely to recall negative self-descriptors (Millham \& Kellogg, 1980; Paulhus \& John, 1998; Sackeim \& Gur, 1979). In contrast, persons who score high on the Alpha factor are marked by the personality factors Extraversion and Openness and report lower levels of distress and more positive affect (Paulhus \& John, 1998). Furthermore, King et al. (1992) found the Self-Deception Questionnaire (SDQ; Sackeim \& Gur, 1979), associated with the Alpha factor, negatively correlated with self-concealment. Thus, although the relationship between self-concealment and social desirability remains unknown, self-concealers' reports of high distress together with their potential need for affiliation or approval could support conceptualizing them as high on the Gamma factor of social desirability. However, this postulation necessitates support from future research. 
Still, what remains clear is the strong link between self-concealment and distress (Larson \& Chastain, 1990). Neuroticism is a personality characteristic that is associated with distress and has been associated with self-concealment (Wismeijer \& van Assen, 2008)

\section{Neuroticism.}

Neuroticism, as conceptualized by Eysenck and often measured by the Eysenck Personality Questionnaire (EPQ; Eysenck \& Eysenck, 1975), is generally understood as a personality characteristic associated with negative affectivity, emotional instability, negative complaints, susceptibility to stress, and anxiety proneness. Larson and Chastain (1990) suggested that neuroticism may explain the relationship between self-concealment and complaints of negative symptomatology. Wismeijer and van Assen (2008) examined whether neuroticism mediated the relationship between self-concealment and well-being. They used a Dutch translation of Mowen's Personality Scale (Mowen, 2000), based on a five-factor personality model, to test their hypothesis. Self-concealment was positively associated with neuroticism $(r=.17)$. Consistent with their hypothesis, neuroticism accounted for approximately $39 \%$ of the relationship between self-concealment and subjective well-being. Kahn and Hessling (2001) similarly found a positive relationship between self-concealment and neuroticism $(r=.36)$ as measured by the Five-Factor Inventory (FFI; Costa \& McCrae, 1992). Furthermore, Kahn et al. (2002) found self-concealment positively related to negative affectivity $(r=.41)$ and negatively related to positive affectivity $(r=-.31)$ on the PANAS (Watson et al., 1988). Wismeijer and van Assen (2008) concluded that neuroticism accounts for a 
significant portion of the relationship between self-concealment and subjective wellbeing, but acknowledged that over $60 \%$ of the relationship remains unexplained. Wismeijer and van Assen suggested that future research focus on additional variables to account for this relationship, including inhibitory constructs (examined later in this study). In addition to neuroticism, self-concealment may be related to shame-proneness.

\section{Shame-proneness.}

Shame involves experiencing painfully negative feelings or thoughts about the self and/or concern about negative evaluation or scrutiny from others, both with a fear of being exposed and an ensuing desire to escape or hide (Gilbert, 1998; Tangney, Wagner, \& Gramzow, 1992). Shame may develop from traumatic experiences, and characteristics of one's personality, or one's degree of shameproneness may moderate susceptibility to experience shame with or without the presence of trauma (Gilbert, 1998). The Test of Self-Conscious Affect (TOSCA; Tangney, Wagner, \& Gramzow, 1989) is a 15 -item instrument that measures shameproneness by asking participants to identify on Likert-type scales the degree to which different responses reflect their likely reaction to a presented scenario. The different response choices reflect characteristics of shame, guilt, detachment/unconcern, pride in self, and pride in behavior, and participants receive scores on each of these indices. For example, for the item "You make a mistake at work and find out a coworker is blamed for the error," the shame-proneness response is "You would keep quiet and avoid the coworker." Tangney et al. (1992) 
linked shame-proneness to numerous measures of psychopathology, including anxiety, depression, and interpersonal sensitivity.

Research has connected shame to non-disclosure. A qualitative study with an outpatient clinical sample found participants' reported reasons for non-disclosure of everyday emotional experiences fell into two broad categories relating to either negative perceptions of themselves or concern about negative perceptions from others (MacDonald \& Morely, 2001). Pineles, Street, and Koenen (2006) suggested that shame leads to self-concealment because a person experiencing shame fears punishment associated with disclosing negative information about the self. Shameproneness, as measured by TOSCA, positively correlated with self-concealment $(r=$ .38) among female college students (Pineles et al., 2006). Furthermore, shameproneness positively predicted self-concealment, and self-concealment fully mediated the relationship between shame-proneness and psychological symptoms, as measured by the General Severity Index (GSI) of the Brief Symptom Inventory (BSI; Derogatis \& Melisaratos, 1983). Self-concealment also partially mediated the relationship between shame-proneness and PTSD symptoms, but did not mediate the relationship between shame-proneness and stress-related physical symptoms.

A connection clearly exists between self-concealment and shame. Pineles et al. (2006) suggested that shame-proneness leads to self-concealment, which then leads to psychopathology. In support, self-concealment mediated the relationship between shame and psychological symptoms (Pineles et al., 2006). However, shame does not appear to explain the relationship between self-concealment and negative symptoms. The next section focuses on behavioral inhibition and why it may 
account for the relationship between self-concealment and negative symptomatology. A strong body of research ties behavioral inhibition to physiological arousal and psychological problems. This provides a foundation from which to hypothesize about the link between self-concealment, behavioral inhibition, and negative symptomatology.

\section{Behavioral inhibition}

Anita Kelly (2002) proposed that the relationship between self-concealment and negative symptomatology could be explained through behavioral inhibition. She suggested that persons who self-conceal are unhealthier, before ever selfconcealing, because they are behaviorally inhibited. She noted that behaviorally inhibited persons have a genetic predisposition for health problems and that behavioral inhibition, rather than effects from keeping secrets, accounts for association between self-concealment and negative symptomatology. Kelly's supposition regarding the connection between self-concealment and behavioral inhibition has yet to be empirically examined. The present research will begin to investigate this hypothesis.

Kelly (2002) defined behavioral inhibition as a tendency to be easily aroused by novel stimuli. This definition of behavioral inhibition fits with those provided by child temperament theorists, such as Kagan (1997). Childhood anxiety research generally characterizes behavioral inhibition as an inborn, temperament-based characteristic exemplified in unusually shy children, who react in fear and withdrawal in new or unfamiliar situations (Muris \& Dietvorst, 2006). An adaptive function generally present in all children and newborn mammals, behavioral 
inhibition tends to disappear as children age, learn about their environment, and build coping skills (Muris \& Dietvorst, 2006). However, when it remains significantly present, it serves as a risk factor for childhood anxiety disorders (Muris $\&$ Meesters, 2002). Such conceptualizations of behavioral inhibition focus on sensitivity to novel stimuli. This definition can be differentiated from theories that conceptualize behavioral inhibition as sensitivity to punishment. It is this latter conceptualization of behavioral inhibition, derived from animal learning and behavior, which will be the focus of this investigation.

\section{Reinforcement Sensitivity Theory}

Jeffrey A. Gray (1987) proposed three neurobiological systems underlie behavior and affect: the behavioral inhibition system (BIS), the behavioral approach system (BAS), and a fight/flight system. The BIS and BAS are the focus of this investigation. Their accompanying theory, the reinforcement sensitivity theory (RST; Pickering, 1997), maintains that the BIS and BAS respectively regulate sensitivities to cues of punishment and reward. These sensitivities are orthogonal, and, accordingly, persons can have all combinations of BIS and BAS sensitivities.

The BIS is sensitive to cues in the environment that have been conditioned or reinforced, through experience, to signify threat or punishment. Persons with higher BIS sensitivities are better at picking up on cues that signal impending punishment. BIS stimulation contributes to increased arousal, attention to the environment, and negative emotion, particularly anxiety (Carver, 2004; Carver \& White, 1994; Gray, 1991). Persons with high BIS sensitivities typically deal with 
their anxiety through passive avoidance. This is in comparison to persons with high BAS sensitivities who may avert punishment through more active methods.

The BAS is sensitive to signals reinforced to bring reward. Persons with higher BAS sensitivities are more likely to be activated by situations with positive incentives. The BAS is associated with pursuing rewards and reacting with upbeat emotion (eagerness, excitement, and elation) when working toward and receiving rewards (Carver, 2004). This is in contrast to persons with high BIS sensitivities, who may experience feelings of relaxation in the same contexts (Higgins, Shah, \& Friedman, 1997). The BAS has also been connected to some negative emotions (previously attributed to the BIS), including frustration during goal pursuit (Carver, 2004). Physiological research describes processes and brain functions connected to BIS and BAS activity.

Physiological research on the BIS and BAS initially developed from animal research that studied the disinhibition effects of anxiolytic drugs, including alcohol (Gray, 1970). Gray (1991) described the septal-hippocampus as a major component of behavioral inhibition. Electroencephalographic (EEG) and neuroimaging data further suggest involvement of the right prefrontal cortex with the BIS (Davidson, Ekman, Saron, Senulis, \& Friesen, 1990). Also, skin conductance responses emerge with activation of the BIS, but not the BAS (Fowles, 1988).

BAS activity has been related to dopaminergic fibers and secreting neurons of the ventral legmental area (Gray, 1991; Depue \& Collins, 1999). EEG and neuroimaging data further indicate that movement toward reward is associated with the left prefrontal cerebral cortex (Davidson et al., 1990). Also, heart rate increases 
with BAS, but not BIS, activation (Fowles, 1988). A large amount of research on the physiological underpinning of the BIS and BAS exists. However, this study focuses on emotion and behavior that stem from the systems.

\section{Behavioral Inhibition/Behavioral Activation Scale (BIS/BAS).}

Carver and White (1994) developed the Behavioral Inhibition/Behavioral Activation Scale (BIS/BAS) to assess individual sensitivities of the BIS and BAS. Carver and White explained that a new instrument was needed because the current assessments of behavioral inhibition and behavioral approach, such as the MacAndrew and Steele (1991) measure of BIS sensitivity, were not consistent with conceptualizations by Gray. Instead, these measures generally tapped feelings and behaviors (i.e., anxiety) that already occurred, rather than one's susceptibility to them. Carver and White explained that a person with high BIS sensitivity may design his or her life in such a way as to limit the degree to which he or she is exposed to anxiety-provoking things and, therefore, may not experience considerable amounts of anxiety (Fowles, 1987). Hence, Carver and White designed the BIS/BAS to measure susceptibility to cues of punishment and reward.

The BIS/BAS (Carver \& White, 1994) is a self-report instrument that consists of one BIS and three BAS scales. The three BAS subscales are Reward Responsiveness, Drive, and Fun Seeking. The BAS scales are moderately correlated and have been shown to be part of the same larger-order BAS factor (Jorm et al., 1999; Smillie, Jackson, \& Dalglish, 2006; Zelenski \& Larsen, 1999).

Convergent and discriminative validity analyses indicate the BIS/BAS to be associated with, but distinct from, related instruments (Carver \& White, 1994). 
Carver and White (1994) found the BIS scale to correlate positively with the Manifest Anxiety Scale (Taylor, 1953), the California Psychology Inventory's Socialization scale (Gough, 1956, 1960), the PANAS Negative Affectivity scale (Watson et al., 1988), and the General Temperament Survey's (GTS) measure of negative temperament (Watson \& Clark, 1993). BIS scores correlated negatively with the Life Orientation Test's (LOT) measure of optimism (Scheier \& Carver, 1985) and the Disinhibition scale of GTS. The BIS scale correlated positively with three other behavioral inhibition instruments, including MacAndrew and Steele's (1991) measure of BIS sensitivity, Torrubia and Tobena's (1984) Susceptibility to Punishment scale, and the Harm Avoidance scale of the Tridimensional Personality Questionnaire (TPQ; Cloninger, 1987). The BIS also positively correlated with the TPQ Reward Dependence scale. Although the Reward Dependence scale was designed to measure the BAS, Carver and White suggested its relationship with the BIS may be related to this scale's focus on seeking social rewards, which may tap sensitivity to disapproval from others.

Carver and White (1994) also assessed convergent and discriminant validity of the BAS scales. When compared to a 10-item extraversion scale (Eysenck \& Eysenck, 1985) all three BAS subscales, Reward Responsiveness, Drive, and Fun Seeking, correlated positively. All three scales also had positive relationships with positive affectivity and positive temperament, as measured by the PANAS-PA and GTS. Reward Responsiveness related positively to Reward Dependence on the TPQ. Drive correlated positively to Hypomania on the Minnesota Multiphasic Personality Scale (MMPI), optimism on the LOT, and disinhibition on the GTS. Fun 
Seeking was related to Hypomania, disinhibition, and Novelty Seeking on the TPQ. Negative correlations were found between Drive and Harm Avoidance on the TPQ. Fun Seeking negatively correlated with Socialization on the CPI, Susceptibility to Punishment (Torrubia \& Tobena, 1984), and the TPQ's Harm Avoidance. Carver and White concluded the BIS/BAS to have sound convergent and discriminant validity, and subsequent research similarly also found convergent and discriminant validity (e.g., Gomez \& Gomez, 2005). Carver and White designed laboratory studies to assess construct validity.

Carver and White (1994) designed an experiment to engage the BIS irrespective of the BAS by creating the perception of punishment without the perception of reward. Participants (undergraduate students) were made to believe that their performance on a pattern recognition test, on which all participants received equally poor feedback, would determine the amount of time they had to immerse their hand in very cold water. The criterion variable was feelings of nervousness, as measured by a single item embedded among items measuring other emotions. Results revealed that BIS scores predicted the degree to which participants reported being nervous, prior to receiving punishment. Furthermore, BIS scores were better predictors of nervousness than trait anxiety, as measured by the Manifest Anxiety Scale (MAS; Taylor, 1953). As hypothesized, BAS scores were not related to reports of nervousness.

Carver and White (1994) carried out a similar study to engage the BAS irrespective of the BIS. Participants were made to believe that they would be receiving a reward without the perception of punishment. Using a similar pattern 
recognition setup, participants were informed that good performance on the task would result in earning additional experiment credits. All participants received the same positive feedback indicating that their performance enabled them to receive extra credits. The criterion variable was their degree of happiness, as measured by a single item embedded among items that assessed other emotions. Only extraversion, as measured by 10 items (Eysenck \& Eysenck, 1985), related to initial levels of happiness. However, all BAS scales and extraversion related to levels of happiness after being informed that their performance qualified them for extra credit. After controlling for levels of initial happiness only Drive, followed by Reward Responsiveness, predicted participants' reported happiness. The BIS was not related to happiness. While the BIS and the BAS have received empirical support corroborating their validities as distinct from related constructs, research has also attempted to find commonalities between the BIS and BAS and other models of personality.

\section{Factor analyses with Eysenck's personality dimensions.}

The BIS/BAS (Carver \& White, 1994) has been combined and submitted to factor analyses with other personality instruments similarly based on theories by Gray and Eysenck (Caseras, Avila, \& Torrubia, 2003; Smillie et al., 2006; Zelenski \& Larsen, 1999). Three factors generally emerge. One factor is a punishment sensitivity factor onto which the BIS and Neuroticism load. Another is a reward sensitivity factor on which both Reward Responsiveness and Drive load. Fun Seeking falls on a separate impulsiveness/thrill-seeking factor that includes 
Psychotocism (Caseras et al., 2003; Smillie et al., 2006; Zelenski \& Larsen, 1999). These three factors are similar to those found in three-factor personality models.

There is debate as to whether three-factor personality models such as Eysenck's (Extroversion, Neuroticism, and Psychoticism/Constraint) or five-factor personality models (with the five-factors being combined as Neuroticism, Extraversion/Sociability, and Conscientiousness/Agreeableness) better account for behavioral inhibition and behavioral approach (Nigg, 2000; Zuckerman, Kuhlman, Joireman, Teta, \& Kraft, 1993). Gray (1991) contends that a primary difference between his and Eysenck's theory lies where the constructs fall in conceptual factor space, with Neuroticism and Extraversion on perpendicular axes. Gray proposed that high BIS falls between neuroticism and introversion, but closer to introversion and high BAS falls between neuroticism and extraversion, but closer to extraversion (Pickering, Corr, \& Gray, 1999).

Although factor analyses offer a three factor solution, research also supports two superordinate factors, consistent with a BIS/BAS model. Following factor analysis with oblique rotation the punishment sensitivity factor did not correlate strongly with the reward sensitivity and impulsiveness factors, which displayed the highest correlation (Caseras et al., 2003). Also, when Caseras et al. (2003) forced a two factor solution with an oblique rotation, the two factors were uncorrelated and accounted for $48.3 \%$ of the variance. Smillie et al. (2006) also found two BAS factors, and the internal consistency of the BAS total score was .81 , indicative of high internal consistency among all BAS items. 
Distinctions exist between behavioral inhibition, behavioral approach, and Eysenck's personality factors. Although the BIS shows moderate to strong correlations ( $r=.54$ to .84$)$ with various indices of neuroticism (Carver, 2004; Caseras et al., 2003; Gomez \& Gomez, 2005), behavioral inhibition and neuroticism theoretically capture different qualities. Neuroticism gauges the amount of negative emotion experienced (Eysenck, 1947), and the BIS reflects sensitivity to cues of punishment (Gray, 1991). A significant difference between the two may present itself when a person high in behavioral inhibition copes with anxiety by designing his or her life to avoid anxiety cues. Thus, although the person is especially susceptible to anxiety, significant negative emotion is not experienced on a typical day (Fowles, 1987). In support, when negative emotion was measured in the specific context of looming punishment, the BIS predicted nervousness better than neuroticism (Carver \& White, 1994).

As with BIS and neuroticism, the BAS differs from extraversion. Extraversion has a considerable element of sociability (Eysenck, 1947). However, sociability is not a clear component of the BAS, which predicts movement toward and positive emotion with reward stimuli (Carver \& White, 1994). In the face of reward, Drive and Reward Responsiveness predicted happiness over and above that of extraversion (Carver \& White, 1994).

Evidence supports discriminating Gray's model from other personality models. However, this differentiation is not an attempt to deny shared phenotypical behavior and physiological mechanisms (Nigg, 2000). To the contrary, finding commonalities between models can help establish macro-level conceptualizations of 
human behavior. For example, a higher order factor with multiple measures of avoidance (e.g., BIS, neuroticism, negative affectivity, etc.) served as the best correlate to mental health problems rather than any one measurement alone (Larsen \& Augustine, 2008). Similar results were also found with instruments that measured the approach paradigm (e.g., BAS, extroversion) (Larsen \& Augustine, 2008). With this taken into consideration, this research focuses specifically on behavioral inhibition and behavioral approach, as measured by the BIS/BAS (Carver \& White, 1994) in order to contribute to a better understanding of how these constructs relate to self-concealment. BIS-related findings will next be examined.

\section{Behavioral inhibition system (BIS).}

The behavioral inhibition system (BIS) is a system that is sensitive to cues of punishment and should predict anxiety in situations where such a threat exists. In support, BIS scores predicted participants' nervousness after receiving feedback that their performance failed to meet qualification for a reward, and BIS scores predicted participants' nervousness after imagining their responses to anxiety and anger producing scenarios (Carver, 2004). Additionally, BIS scores predicted levels of fear when surveyed about the September $11^{\text {th }}$ attacks (Carver, 2004). Jorm et al. (1999) found BIS scores correlated with negative affectivity as measured by the PANAS (Watson et al., 1988). Johnson, Turner, and Iwata (2003) found BIS scores positively related to anxiety disorders and diagnoses of depression among young adolescents as measured by a Michigan revision of the Composite International Diagnostic Interview (CIDI; Kessler, 1994). Alloy et al. (2008) found BIS scores related to higher depressive symptoms $(r=.21)$ and lower (hypo) manic symptoms 
$(r=-.19)$. Finally, women generally show higher BIS scores than males (Carver \& White, 1994, Study 1; Caseras et al., 2003; Johnson et al., 2003; Jorm et al., 1999; Kashdan \& Roberts, 2006, Study 1; Leone, Perugini, Bagozzi, Pierro, \& Mannetti, 2001). This research lays the foundation for examining a potential positive relationship between behavioral inhibition and self-concealment.

\section{The relationship between the BIS and self-concealment.}

It has been suggested that self-concealers are inherently unhealthier due to behavioral inhibition, and behavioral inhibition may mediate the relationship between self-concealment and negative health (Kelly, 2002; Larson \& Chastain, 1990). When faced with cues of punishment, persons high in behavioral inhibition experience significant anxiety that they manage through avoidance. I am suggesting that self-concealment may be a byproduct of avoidant behavior produced by anxiety about potential punishment. While self-concealment and behavioral inhibition do not appear to have been directly compared, their established relationships with other variables suggest a connection between the two constructs.

Self-concealment and behavioral inhibition both show consistent relationships to reports of anxiety and depression (Carver \& White, 1994; Larson \& Chastain, 1990), neuroticism (Carver, 2004; Caseras et al., 2003; Gomez \& Gomez, 2005; Kahn \& Hessling, 2001; Wismeijer \& van Assen, 2008), and negative affectivity (Jorm et al., 1999; Kahn \& Hessling, 2001). Self-concealment also associates with constructs conceptually connected to behavioral inhibition and threat-sensitivity. Ichiyama et al. (1993) found a positive relationship between selfconcealment and shyness $(r=.30)$ using the Social Reticence Scale (Jones \& 
Briggs, 1986), and self-concealment related to interpersonal distance among Japanese college students (Yukawa et al., 2007). Furthermore, self-concealers' increased likelihood to self-disclose to a counselor over a friend or family member could reflect their belief that disclosure to family and friends is more likely to result in punishment (Kawamura \& Frost, 2004). Among women, self-concealment was associated with perfectionism, which has been also conceptualized as fear of punishment associated with mistakes (DiBartolo et al., 2008; Kawamura \& Frost, 2004). Also among women, DiBartolo et al. (2008) found self-concealment associated with fears of negative evaluation $(r=.39)$, as measured by the Fear of Negative Evaluation-Brief Version (Brief FNE; Watson \& Friend, 1969). Furthermore, self-concealment connects to shame-proneness, which has been characterized as concern about scrutiny from others (Pineles et al., 2006). Finally, the development of behavioral inhibition appears to mirror Gilbert's (1998) description of the development of shame: punishment cues are conditioned to elicit intense anxiety. The above research gives support to the hypothesis, examined in this study, that a connection exists between self-concealment and behavioral inhibition. Behavioral approach may provide additional ways to conceptualize and understand self-concealment.

\section{Behavioral approach system (BAS).}

Burgeoning amounts of research have investigated the behavioral approach system, also known as the behavioral activation system (BAS; Fowles, 1980). It has been theorized as an important factor in biologically-based personality theories, including those focusing on deviant or antisocial behaviors (e.g., Johnson et al., 
2003). Reward Responsiveness, Drive, and Fun Seeking, the three BAS scales, all positively correlate with extraversion, positive affectivity, and positive temperament (Carver, 2004; Carver \& White, 1994), but each has different predictive abilities. Since they have differing predictive abilities, looking at only the BAS total score (e.g., Gomez \& Gomez, 2005; Smillie \& Jackson, 2006) could obscure results and conclusions about the BAS. In view of that, the following review focuses on studies that separated the BAS subscales so unique characteristics of each scale can be identified.

\section{reward responsiveness.}

Reward Responsiveness is conceptualized as activation, both with behavior and positive emotion, in the face of potential reward (Carver \& White, 1994). Reward Responsiveness scores predicted bipolar spectrum participants' first hypomanic or manic episode, with higher sensitivities having a shorter onset (Alloy et al., 2008). Although negative affect was originally theorized to relate only to the BIS, Reward Responsiveness predicted, more strongly than the BIS, feelings of anger when participants were made to believe they failed at a task involving a reward and also when surveyed about the September $11^{\text {th }}$ attacks (Carver, 2004). Women generally show higher scores on Reward Responsiveness (Johnson et al., 2003; Leone et al., 2001). However, Carver and White (1994, Study 1) found that women had significantly lower scores than men on Reward Responsiveness. Reward Responsiveness moderately correlates with the BIS and generally covaries with the BIS (Johnson et al., 2003; Leone et al., 2001). For example, Reward Responsiveness shows a positive relationship with depression, anxiety, and negative 
affect (Jorm et al., 1999). It is possible that this positive relationship could stem from Reward Responsiveness' association with negative emotion in reward-related contexts (Carver, 2004).

\section{drive.}

Drive reflects persistence in reaching goals (Carver \& White, 1994). Bipolar participants had higher scores on Drive (Alloy et al., 2008). In a questionnaire assessing feelings following the September $11^{\text {th }}$ attacks, anger correlated significantly with Drive (Carver, 2004). During a study in which participants were made to believe they failed at a task involving a reward, nervousness inversely related to Drive (Carver, 2004).

\section{fun seeking.}

Fun Seeking has been conceptualized as seeking out new and novel rewards and stimuli and spontaneously engaging in potentially rewarding experiences (Carver \& White, 1994). Bipolar participants had higher Fun Seeking scores (Alloy et al., 2008). Carver (2004) found Fun Seeking scores to be a significant correlate of sadness and frustration when participants failed at a task associated with a reward. Johnson et al. (2003) found that high Fun Seeking scores were associated with alcohol problems, but only for those participants whose alcohol problems were not concurrent with anxiety problems. Furthermore, Fun Seeking was associated with drug problems when an alcohol problem existed (Johnson et al., 2003). During a study in which participants were made to believe they failed at a task involving a reward, nervousness was inversely related to Fun Seeking (Carver, 2004). The 
potential relationship between behavioral approach and self-concealment will now be explored.

\section{The relationship between the BAS and self-concealment.}

Self-concealment has not been directly compared to the BAS (Carver \& White, 1994), and the self-concealment research does not seem to offer a clear prediction regarding their relationship. Self-concealment has shown a negative relationship with positive affect and nonsignificant and negative relationships with extraversion, two constructs typically associated with the BAS (Kahn \& Hessling, 2001; Lopez et al., 2002; Wismeijer \& van Assen, 2008). Although Wismeijer and van Assen (2008) hypothesized that extraversion accounted for the relationship between self-concealment and subjective well-being, through its negative association with the desire to socially engage, extraversion did not account for a significant portion of the variance between self-concealment and subjective wellbeing after controlling for neuroticism. This could likewise suggest a weak negative or nonsignificant relationship between behavioral approach and self-concealment. On the other hand, Reward Responsiveness mirrors self-concealment in its positive relationship with measures of negative affectivity (Jorm et al., 1999). Given the limited evidence about the relationship between self-concealment and behavioral approach, together with the multifaceted nature of the BAS, the potential relationship between self-concealment and each BAS scale will next be examined.

Reward Responsiveness is conceptualized as activation, both with behavior and positive emotion in the face of potential reward (Carver \& White, 1994). Are self-concealers particularly motivated by reward? It is possible that self-concealers 
may be less attuned to or motivated by reward, given that those who conceal information are less likely to obtain rewards associated with the disclosure of personal information (Pennebaker \& Chung, 2007). Also, self-concealment negatively relates to extraversion and positive affect, constructs positively related to Reward Responsiveness. Thus, a negative relationship between self-concealment and Reward Responsiveness could be offered. On the other hand, the positive relationship between depression and anxiety and Reward Responsiveness could point to a positive relationship between self-concealment and Reward Responsiveness (Jorm et al., 1999). Due to conflicting and speculative theories regarding the relationship between Reward Responsiveness and self-concealment, it seems prudent to not pose a specific hypothesis regarding their relationship.

Drive has been conceptualized as persistence in reaching goals (Carver \& White, 1994). Drive does not appear to be associated with self-concealment or threat sensitivity constructs. Self-concealment was not related to setting and striving to achieve high standards, as measured by the Personal Standards subscale of the Multidimensional Perfectionism Scale (DiBartolo et al., 2008; Frost et al., 1990; Kawamura \& Frost, 2004). Furthermore, while items on the Drive scale generally reflect the degree persons will go out of their way to get things they want (e.g., Item 11), results from Higgins et al. (1997) suggest that persons with an avoidance orientation, as is being suggested of self-concealers, are more focused on reaching goals associated with obligations and duties, rather than those associated with wants, hopes, and desires. Accordingly, there does not appear to be evidence to support a hypothesis between self-concealment and Drive. 
Fun Seeking has been conceptualized as seeking out new and novel rewards and stimuli and being able to spontaneously engage in potentially rewarding experiences (Carver \& White, 1994). Fun Seeking has been shown to be part of a larger order impulsivity factor (Smillie et al., 2006). This impulsivity factor has been conceptualized as similar to behavioral disinhibition and negatively associated with constraint, conscientiousness, and the general ability to inhibit socially unacceptable impulses and delay gratification to meet social expectations (Nigg, 2000; Zuckerman et al., 1993). It makes sense to conceptualize self-concealers as constraining inclinations and taking fewer risks, particularly since self-concealers do not take the risk of and are able to refrain from revealing personal information. This could suggest a negative relationship between self-concealment and Fun Seeking. However, King et al. (1992) found that self-concealment was related not to a Behavioral Control factor that included multiple measures of constraint, but was instead related to an Emotional Constriction factor. This would suggest that a relationship may not exist between Fun Seeking and self-concealment. Thus, as with Reward Responsiveness and Drive and prediction regarding the relationship between self-concealment and Fun Seeking is not made.

Given limited theory and research surrounding the relationship between selfconcealment and the behavioral approach scales, I do not posit hypotheses regarding the relationships between the behavioral approach scales and self-concealment. However, I do examine whether the BAS scales contribute to variance in selfconcealment above that of behavioral inhibition. I also investigate whether the relationship between self-concealment and the BIS/BAS differs by gender. 


\section{Gender differences in the relationship between the BIS and self-}

\section{concealment.}

Mean self-concealment scores do not consistently vary by gender (Larson \& Chastain, 1990). However, gender differences emerge when examining variables that predict self-concealment. Kawamura and Frost (2004) found a stronger relationship between self-concealment and perfectionism in women $(r=.61)$ than men $(r=.08)$. Also, depression, self-esteem, anxiety, and shyness (all four predictor variables) contributed to self-concealment in women, while only depression predicted self-concealment in men (Ichiyama et al., 1993). Accordingly, the link between self-concealment and negative symptomatology may be different for men and women.

The connection between self-concealment, behavioral inhibition, and negative symptomatology could be stronger for women. Characteristics like anxiety and fear of punishment may be more predictive of self-concealment in women. Qualitatively different variables, in addition to or in place of behavioral inhibition, may be needed to explain the relationship between self-concealment and negative symptomatology in men. In support, different variables have been shown to contribute to psychopathology for men and women.

A longitudinal study revealed that females who reported depressive symptoms at 18-years-old exhibited higher levels of internalized negative affect, oversocialization, control, and intelligence at earlier ages (Block, Gjerde, \& Block, 1991). In comparison, males' depressive symptoms were predicted by lower levels of socialization, lower intelligence, and higher levels of aggression and self- 
aggrandizement (Block et al., 1991). Similarly, Patterson and Capaldi (1990) found support for a model in which depressed mood among boys was predicted by low academic achievement, and this relationship was mediated by peer rejection. Dibble and Swanson (2000) found that among young adults with genital herpes, selfconcealment, anger, decreased vigor, stress, and a negative attitude toward herpes significantly predicted depression scores for women. However, for men selfconcealment did not predict depression. Instead, anger, a negative attitude toward herpes, and self-disclosure to same-sex strangers predicted depression scores. Also, self-concealment was more related to delinquency among male than female adolescents (Frijns et al., 2005). Thus, for men factors like peer relationships and delinquency may be stronger contributing factors to the relationship between selfconcealment and negative symptomatology. For women behavioral inhibition and its related constructs may play a stronger role. Accordingly, it is proposed that an interaction will emerge in which the relationship between self-concealment and behavioral inhibition differs for females and males.

Backgrounds on self-concealment, behavioral inhibition, and behavioral approach have been presented. Self-concealment research alludes to a relationship between self-concealment and behavioral inhibition, with behavioral inhibition potentially mediating the relationship between self-concealment and health (Larson \& Chastain, 1990). The relationship between self-concealment and the BIS/BAS has not had a direct empirical investigation. While taking into consideration that the BIS and BAS are related to and overlap with other psychological constructs, this author postulates that the most parsimonious way to understand self-concealment is as an 
inhibitory mechanism within the approach-avoidance paradigm as conceptualized by Gray and measured by the BIS/BAS (Carver \& White, 1994). Hence, this study empirically investigates the relationship between self-concealment and behavioral inhibition and also examines the relationship between self-concealment and behavioral approach.

\section{The Present Study}

Abundant research has found statistically significant correlations between self-concealment and complaints of physical and psychological problems. Although the studies have typically been correlational in nature, a causal link between selfconcealment and symptomatology had traditionally been assumed. Newer research points to flaws with this interpretation. Kelly and Yip (2006) elucidated that it is not the act of secret-keeping, but rather the personality traits of self-concealers that is related to negative physical and psychological symptoms. Kelly (2002) postulated that the link between self-concealment and negative symptomatology could be explained through behavioral inhibition.

I hypothesize that self-concealment is positively related to behavioral inhibition, given that persons with high behavioral inhibition are sensitive to cues of punishment, such as disapproval from others. Anxiety resulting from punishment cues contributes to avoidance behavior or, in this case, the concealment of negative or distressing information about oneself. This hypothesis fits with the positive relationship self-concealment has with shyness (Ichiyama et al., 1993) and perfectionism (Kawamura \& Frost, 2004). I also hypothesize that significant gender differences will emerge in the relationship between self-concealment and behavioral 
inhibition. This hypothesis is based on research in which more predictor variables associated with behavioral inhibition contribute to self-concealment scores among females than males (Ichiyama et al., 1993).

Accordingly, the following hypotheses are offered:

$\mathrm{H}_{1}$ : Self-concealment, as measured by scores on the SCS, will be positively associated with behavioral inhibition, as measured by scores on BIS subscale of the BIS/BAS.

$\mathrm{H}_{2}$ : The relationship between self-concealment, as measured by scores on the SCS, and behavioral inhibition, as measured by scores on the BIS subscale of the BIS/BAS, will be moderated by gender.

$\mathrm{R}_{1}$ : What is the relationship between self-concealment, as measured by scores on the SCS, and behavioral approach, as measured by scores on the BIS/BAS subscales Reward Responsiveness, Drive, and Fun Seeking?

\section{Method}

\section{Participants}

Participants included 275 adults (171 women, 104 men) from a non-clinical, general population sample. Participants were recruited by placing links to the Internet-based survey's url in messages sent through email and a social networking website. By beginning within the author's social and professional network, snow ball solicitation contributed to accessing a large target nonclinical population 
between the ages of 18 and 64 . As a small incentive to provide self-report data, participants had the option of being included in two drawings for a \$75 Wal-Mart gift card. One hundred ninety-four persons entered the drawing. One in 97 persons won a gift certificate.

\section{Instruments}

\section{Self-Concealment Scale (Larson \& Chastain, 1990).}

The Self-Concealment Scale (SCS; Larson \& Chastain, 1990) is a 10-item self-report scale that asks participants to indicate on a 5-point Likert-type scale the degree to which they agree or disagree with particular items (see Appendix A). Larson and Chastain (1990) initially validated the scale on 277 female and 29 male human services workers, counseling psychology students, and attendees at a professional training (at which one of the authors delivered an address). Coefficient alpha estimated the internal consistency of the SCS to be $\alpha=.83(N=306)$. Using an independent sample of 43 female counseling psychology students and a fourweek time interval, a test-retest reliability of $r=.81$ was determined. Mean SCS scores for a college student sample were 26.49 with a standard deviation of 7.97 (Kahn \& Hessling, 2001).

Larson and Chastain (1990) also performed an exploratory maximum likelihood factor analysis of the SCS. This resulted in two eigenvalues greater than 1. However, Larson and Chastain concluded that the SCS was unidimensional based on the high percentage of common variance (65\%) accounted for by the first factor, the uninterpretableness of the second factor, and the high item loadings on the first factor, which ranged from .46 to .71 . Other indicators of homogeneity included the 
moderate corrected item-total correlations and the mean inter-item correlations of .34. Larson and Chastain concluded from these psychometrics that the SCS appeared to be a largely unidimensional and reliable instrument. Other researchers reported similar psychometric properties with the SCS (e.g., Cepeda-Benito \& Short, 1998; Ichiyama et al., 1993; Kelly \& Archter, 1995).

Cramer and Barry (1999) conducted two studies to analyze the psychometric properties of the SCS. In the first study, the internal consistency estimate $(\alpha=.86)$ was comparable to that of Larson and Chastain (1990). Principal axis factor analysis showed two factors accounted for $55.3 \%$ of the common variance, with the first factor (items 1, 2, 4, 8, and 9) explaining 44.3\% (eigenvalue $=4.43,3.94$, after rotation) and the second factor (items $3,5,6,7$, and 10) explaining $11.0 \%$ (eigenvalue $=1.10,0.81$, after rotation $)$ of the common variance. The first factor was labeled keeping secrets because the concealment was not necessarily selfdirected. The second factor was labeled personal concealment because the concealment was generally more self-motivated. Both factors evidenced adequate internal consistency scores ( $\alpha=.80$ and .76 , respectively). Also, the two subscale scores were highly correlated $(r=.64)$. Despite the two factors, Cramer and Barry concluded that the SCS was unidimensional and suitable for use in research and clinical work due to the large percentage of variance accounted for by the first factor and the high reliability estimates. Cramer and Barry performed a second study with an independent sample and again found the SCS to be internally consistent and reliable: high internal consistency $(r=.74)$ and reliability $(r=.87)$ after an approximate 7-week time interval. Confirmatory factor analyses produced mixed 
results as to whether a one or two factor model was superior. Cramer and Barry posited that "the unidimensional solution was deemed the most comprehensive, efficient, and parsimonious" (p. 636), but suggested that future researchers continue to examine the feasibility of a two factor solution, for example, by comparing the two subscales to indices of maladjustment. Ad hoc analyses of the two SCS factors were completed in this study.

\section{Behavioral Inhibition/Behavioral Activation Scale (Carver \& White,} 1994).

The Behavioral Inhibition/Behavioral Activation Scale (BIS/BAS; Carver \& White, 1994) is a 20-item self-report measure on which participants rate, on 4-point Likert-type scales, the degree they agree or disagree with particular items (see Appendix C). The instrument has four scales: one BIS scale and three BAS scales. The BIS scale (7 items) measures the degree to which participants anticipate feeling anxious when presented with cues of punishment (e.g., "I feel worried when I think I have done poorly at something"). The BAS scale (13 items) is composed of three subscales: Reward Responsiveness (5 items), Drive (4 items), and Fun Seeking (4 items). Items on the Reward Responsiveness scale measure one's tendency to experience positive reactions when rewards are anticipated (e.g., "When good things happen to me, it affects me strongly"). Items on the Drive scale tap participants' tendencies to actively pursue desired goals (e.g., "When I want something, I usually go all out to get it"). Items on the Fun Seeking scale measure the degree to which respondents approach and spontaneously engage in potentially rewarding events (e.g., "I will often do things for no other reason than they might be fun"). Carver 
and White (1994) found the BIS/BAS to be a valid measure of individual differences in the sensitivity of behavioral inhibition and behavioral approach regulatory systems.

When creating the BIS/BAS Carver and White (1994) developed items that they believed captured the essence of the behavioral inhibition and behavioral approach systems as conceptualized by Gray (1991). Carver and White generated more BAS (13) than BIS items (7), given their conceptualization of the BAS as a more multifaceted trait. A principal components analysis of the 13 BAS items formed three correlated factors. Carver and White then submitted all BIS/BAS items to factor analysis using oblique rotation. Four factors, one BIS and three BAS, with eigenvalues greater than 1 emerged and accounted for $49 \%$ of the overall variance. Consistent with theoretical conceptualizations, the BIS scale was generally independent of the BAS scales. The BIS scale strongly loaded on one factor (.93), and the three BAS scales strongly loaded on a second-order factor (all above .75). Test-retest reliabilities, after an approximate 8-week interval, were .66 for BIS, .59 for Reward Responsiveness, .55 for Drive, and .69 for Fun Seeking. The internal consistency of the BIS scale was .74, and the internal consistencies of the Reward Responsiveness, Drive, and Fun Seeking scales were .73, .76 and .66, respectively (Carver \& White, 1994). Subsequent research found similar internal consistencies for the BIS/BAS: internal consistencies for the BIS scale were $.78, .72$ and .82 (Gomez, Cooper, \& Gomez, 2005; Gomez \& Gomez, 2005; Heubeck, Wilkinson, Cologon, 1998); internal consistencies for the Reward Responsiveness scale were .68 and .69; internal consistencies for the Drive scale were .83 and .82 ; and internal 
consistencies for the Fun Seeking scale were .68 and .76 (Gomez et al., 2005; Heubeck et al., 1998).

Moderate correlations exist between the BIS/BAS scales. The BAS is generally unrelated to the BIS, except for a moderate correlation between the BIS and Reward Responsiveness (e.g., Carver, 2004; Carver \& White, 1994; Heubeck et al., 1998; Johnson et al, 2003; Leone et al., 2001; Smillie et al., 2006). A correlation of $r=.28$ and $r=.41$ was found between BIS and Reward Responsiveness by Carver and White (1994) and Carver (2004), respectively. The BAS subscales also generally show moderate correlations. For example, Jorm et al. (1999) found Reward Responsiveness to correlate with Drive $(r=.42)$ and with Fun Seeking $(r=$ .45). Drive also correlated with Fun Seeking $(r=.52)$.

Heubeck et al. (1998) attempted to replicate Carver and White's (1994) principal components analysis. Like Carver and White, Heubeck and colleagues extracted four factors from the BIS/BAS. The factors accounted for $51.5 \%$ of the variation. Confirmatory factor analysis verified that a four-factor correlated model best represented the data, and a two-factor model (BIS and BAS only, as proposed by Jorm et al., 1999) did not fit the data well (Heubeck et al., 1998). Leone et al. (2001) also replicated the four-factor structure using confirmatory factor analysis. Leone et al. altered the BIS/BAS items to have five-point instead of four-point Likert-type scales to improve psychometrics during the maximum likelihood factor analysis procedures. Results indicated that a four-factor model fit satisfactorily in all three samples, and a two-factor model failed to account for sufficient variance in the data (Leone et al., 2001). Johnson et al. (2003) found factor congruence between 
their sample and the Carver and White validation sample using principal components analysis. All items, except for the two reverse-scored BIS items, which formed their own factor, loaded on the four predicted factors, with factor convergence scores above .80 (Johnson et al., 2003).

Gomez et al. (2005) examined the BIS/BAS using an item response theory analysis. They found that the Reward Responsiveness scale showed the most limitations. Two of its 5 items ("It would excite me to win a contest" and "When I get something I want I feel excited and energized") showed only moderate discrimination ability and low item information values. Also, all Reward Responsiveness items were only effective in representing the trait at very low levels to just above the mean. All BIS items, except for one, and all Drive and Fun Seeking items represented and discriminated traits reasonably and reliably when the scores were at least 2 standard deviations below to about 1 standard deviation above the mean. At levels high above the mean, the BIS item "I have very few fears compared to my friends" showed reliable and good representation, but only moderate discrimination ability. Out of all the items, only the Drive item "When I go after something I take a 'no holds barred' approach" was described as having reasonable item response characteristics. It had a high discrimination parameter, a threshold parameter range from about 2 standard deviations below to 2 standard deviations above the mean, and a clear separation in its category response curves (CRCs). Gomez et al. cautioned that from a classical test theory (CTT) perspective, the BIS/BAS showed significant limitations in its psychometric properties and recommended improving the BIS item "I have very few fears compared to my 
friends" and the Reward Responsiveness items "It would excite me to win a contest" and "When I see a good opportunity for something I like, I get excited right away" to increase their discrimination and ability to represent and reliably measure higher trait levels. Additionally, Reward Responsiveness items could increase their differentiation by changing to dichotomous "yes" and "no" responses. Despite limitations in the BIS/BAS scale, it is still the most frequently used tool to assess the behavioral inhibition and activation systems (Alloy et al., 2008), and it was used in its original form, as designed by Carver and White (1994), for this study.

\section{Procedure}

An online survey through SurveyMonkey.com was used to administer this study. The online survey included the Larson and Chastain (1990) SelfConcealment Scale (SCS; 10 items), the Carver and White (1994) Behavioral Inhibition System/Behavioral Activation System Scale (BIS/BAS; 20 items), and demographic questions (gender, age, ethnicity). The survey was prefaced with information to allow informed consent (see Appendix E). The BIS/BAS Scale was presented first, followed by the SCS and demographic questions. It is estimated to have taken participants approximately 10 minutes to complete the survey. Data was collected between June and August 2009.

\section{Results}

A total of 171 females and 104 males completed the survey. With seven variables (SCS, BIS, Reward Responsiveness, Drive, Fun Seeking, gender, and age) a minimal sample size of 53 males and 53 females was determined necessary to provide a 15:1 participant-variable ratio for adequate parameter estimates and power 
(Stevens, 1999). The 171 female and 104 male participants allowed for parameter and power estimates to be met.

The majority of the 275 participants $(62 \% ; n=171)$ were women. The participants ranged from 19 to 63 years of age. The participants' average age was 35.91 years, with a median and mode of 31 and 28 years of age, respectively.

The sample was primarily Caucasian $(85.8 \% ; n=236)$. Approximately $4 \%$ $(n=12)$ of the participants identified themselves as Hispanic or a combination of Hispanic and Caucasian. About 3\% $(n=9)$ of the sample reported being Asian or a combination of Asian and Caucasian. Seven participants (about 3\% of the sample) reported their ethnicity as Native American or as a combination of Native American and Caucasian. Five participants (about $2 \%$ of the sample) identified themselves as African American. One participant identified as Asian Indian, and another identified as Pacific Islander. Two participants reported their ethnicity as multi-racial. One participant reported "other," and 1 participant left the question blank.

Twenty-nine out of 275 participants had missing data on the 30 -item survey. For those 29 participants, 1 participant had 3 missing items, 8 participants had 2 missing items, and 20 participants had 1 item missing. Missing data was handed through pairwise deletion. In other words, only when data was missing on the variable currently being calculated were cases omitted.

To check for outliers SCS, BIS, Reward Responsiveness, Drive, and Fun Seeking total scores were each converted to z-scores. One female participant had a z-score more than 3 standard deviations above the mean (3.29) on Fun Seeking. Her data was consequently removed from subsequent analyses. 
Alpha coefficients of reliability were found to be between .87 and .64 . The Cronbach's alpha for the Self-Concealment Scale was .87. The Cronbach's alpha for the BIS scale was .79. Reliabilities for the BAS subscales Reward Responsiveness, Drive, and Fun Seeking were .70, .82, and .64, respectively. Internal reliability coefficients are also presented in Table 1.

Box's Test of Equality of Covariance Matrices indicated that the variances of the dependent variables were not significantly different from the normal curve, $F$ $(1,244)=1.25, p=.20$. Levene's Test of Equality of Error Variance revealed that the error variance did not significantly vary at a univariate level for SCS, BIS, Reward Responsiveness, Drive, and Fun Seeking. Levene's Test was significant for the variable age $(p=.012)$, but since age was not a significant theoretical or statistical component of the planned analyses, no steps were taken to transform the data.

Mean scores and standard deviations are displayed in Table 1. A multivariate analysis of variance (MANOVA) was used to assess for gender differences. Gender was the independent variable, and SCS, BIS, Reward Responsiveness, Drive, and Fun Seeking scores and age were the dependent variables. The MANOVA revealed significant differences for gender, Wilks' lambda $=.86, F(1,244)=6.50, p<.001$, $p^{2}=.14$. Follow-up analysis of variance (ANOVA) analyses indicated significant gender differences for BIS scores, $F(1,245)=25.41, p<.001$. Although women were expected to display higher BIS scores, men scored higher $(M=15.22, S D=$ 2.87) than women $(M=13.28, S D=2.97)$ on behavioral inhibition. No other significant gender differences emerged. 
As expected, there was not a significant difference between SCS scores for female $(M=34.39, S D=7.60)$ and male $(M=32.85, S D=7.37)$ participants, $F(1$, $244)=2.44, p=.12, \quad p^{2}=.01$. Significant gender differences were also not found for Reward Responsiveness, Drive, and Fun Seeking. Additionally, no significant differences existed between the ages of male $(M=34.42, S D=9.45)$ and female $(M$ $=35.83, S D=11.41)$ participants, $F(1,244)=1.02, p=.31, \quad p^{2}=.004$. Given that significant gender differences emerged for behavioral inhibition, all subsequent analyses were conducted separately for males and females.

Bivariate correlational analyses were used to check for multicollinearity and interrelationships between the variables. Pearson product-moment correlations between the variables are displayed in Table 2. The strongest correlation was between females' Reward Responsiveness and Fun Seeking scores $(r=.50, p<$ .001). This moderate correlation indicates that multicollinerity was not present.

Hypothesis 1 suggests that a significant positive correlation exists between SCS and BIS scores. A significant positive correlation emerged between SCS and BIS scores for women $(r=.24, p=.002)$ and for men $(r=.28, p=.006)$. Hypothesis 1 was, thus, supported.

Hypothesis 2 posited that a gender interaction existed between SCS and BIS scores. An interaction term was created and included in a regression analysis. Results were not significant. In other words, the relationship between selfconcealment and behavioral inhibition was not moderated by gender.

Research Question 1 inquired about the relationship between selfconcealment and behavioral approach. Hierarchical multiple regressions using 
stepwise selection were performed for males and females to determine if BAS scores, when added to BIS scores, added explanatory value to self-concealment. BIS was loaded onto the first predictor block; the second predictor block included Reward Responsiveness, Drive, and Fun Seeking. Multiple regressions are presented in Table 3 .

Behavioral approach did not account for additional explanatory value in selfconcealment among female participants. BIS was the only variable to account for significant variance in self-concealment among women, $F(1,152)=9.553, p=.002$. Behavioral inhibition explained about $6 \%$ of variance in self-concealment, $R^{2}=$ .059 .

Behavioral approach did explain additional variance in self-concealment for male participants. For males, the first presented model included only Fun Seeking as a predictor and accounted for about $8 \%$ of variance in self-concealment, $F(1,94)=$ $8.626, p=.004, R^{2}=.084$. The second model used Fun Seeking and BIS as predictors and accounted for about $17 \%$ of the variance, $F(2,93)=9.499, p<.001$, $R^{2}=.170$. A third model included Fun Seeking, BIS, and Reward Responsiveness. It accounted for the most explanatory value, about $21 \%$, in self-concealment, $F(3,92)$ $=8.048, p<.001, R^{2}=.208$

The correlation between Fun Seeking and self-concealment increased after controlling for the influence of the other predictors, $r_{p}=.375$. This was also true for the relationship between behavioral inhibition and self-concealment, $r_{p}=.355$. The contribution of Reward Responsiveness to self-concealment was in the negative direction and also increased after controlling for the other predictors, $r_{p}=-.215$. 
Post hoc analyses examined two previously identified factors on the SCS (Cramer \& Barry, 1999; Larson \& Chastain, 1990). Exploratory factor analysis employing a Varimax rotation yielded two factors with eigenvalues larger than 1, which together accounted for $57 \%$ of the total variance in self-concealment. The first factor, previously labeled keeping secrets (Cramer \& Barry, 1999) included items $1,2,4,8$, and 9 and explained $47.20 \%$ of variance before and $35.04 \%$ of variance after the rotation. The second factor, previously labeled personal concealment (Cramer \& Barry, 1999) included items 3, 5, 6, 7, and 10 explained $10.21 \%$ of the variance before and $22.37 \%$ of the variance after rotation.

Post hoc bivariate correlations between behavioral inhibition and age were conducted for men and women to explore whether the higher BIS scores among men might be related to age. A significant positive correlation between behavioral inhibition and age emerged for women $(r=.22, p=.004)$. No significant relationship emerged for men $(r=.06, p=.55)$.

\section{Discussion}

This study reviewed and examined the construct of self-concealment. Research shows that self-concealers are more likely to report physical and psychological complaints. Kelly (2002) proposed that behavioral inhibition might explain the link between self-concealment and negative symptomatology. Building on this supposition, behavioral inhibition was hypothesized to positively associate with self-concealment, given that self-concealers may be more sensitive to cues of punishment and, accordingly, avoid self-disclosures that could result in disapproval from others. Moreover, persons high in behavioral inhibition tend to deal with 
anxiety through avoidance, and this avoidance could contribute to or maintain selfconcealment.

The Self-Concealment Scale (SCS; Larson \& Chastain, 1990) and Behavioral Inhibition/Behavioral Activation Scales (BIS/BAS; Carver \& White, 1994) were used to examine the relationship between self-concealment, behavioral inhibition, and behavioral approach in a nonclinical adult population. Reliability coefficients were adequate and consistent with previous uses with the instruments (e.g., Gomez et al., 2005; Larson \& Chastain, 1990). The SCS showed the strongest internal consistency (.87), while Fun Seeking showed the weakest (.64). Moderate correlations emerged between the three BAS subscales $(r=.46$ to .50$)$ and between the BIS and Reward Responsiveness ( $r=.24$ and .30$)$, which matched findings from previous research (e.g., Carver, 2004; Carver \& White, 1994; Jorm et al., 1999). Furthermore, factor analysis revealed two internal factors of the SCS similar to those that emerged in previous studies (Cramer \& Barry, 1999; Larson \& Chastain, 1990).

Gender differences emerged for behavioral inhibition. Men had significantly higher behavioral inhibition scores than females. This contradicts some previous studies that found higher behavioral inhibition scores among women (Carver \& White, 1994, Study 1; Caseras et al., 2003; Johnson et al., 2003; Jorm et al., 1999; Kashdan \& Roberts, 2006, Study 1; Leone et al., 2001). An examination of these studies revealed they all used young adult or college student samples, except for an Australian adult sample in Jorm et al. (1999). 
It is possible that difference in age between the male participants in this study $\left(M_{\text {age }}=34.42\right)$ compared to the average age of males in the college student samples contributed to this unexpected finding. As males mature, they may become more attuned to negative consequences from their behavior, more self-reflective about their own sensitivity to punishment, and less likely to react, or report reacting, in gender stereotypical ways.

It is alternatively possible that the gender difference in the present study resulted from a relative decrease in behavioral inhibition among the female participants in the present study $\left(M_{\mathrm{age}}=35.29\right.$ years $)$. Higher levels of behavioral inhibition, potentially present for women of traditional college age, may dissipate with increased confidence and maturity and less pressure to conform to gender-role expectations.

To further explore these theories, age and behavioral inhibition were submitted to bivariate correlations. A positive relationship emerged between age and behavioral inhibition for women, but a nonsignificant relationship emerged between behavioral inhibition and age for men. However, given that only 3 male and 4 female participants fell between the ages of 18 to 22 , sufficient data does not exist to make comparisons between the age groups. Still, the positive relationship between age and behavioral inhibition among women could reflect an increased tendency for older cohorts to adhere to feminine characteristics associated with behavioral inhibition. Accordingly, contemporary changes in gender-role socialization could contribute to younger cohorts displaying different behavioral inhibition patterns than exhibited in previous research (Priess, Lindberg, \& Hyde, 
2009). These hypotheses will require examination in future studies. It is also possible that this study's sample differs from that of other samples, in which case the below results should be interpreted with caution.

Consistent with Hypothesis 1, self-concealment related positively to behavioral inhibition for both women and men. Multiple regression analyses revealed that behavioral inhibition significantly predicted self-concealment in both women and men. Among women, behavioral inhibition accounted for approximately $6 \%$ of variance in self-concealment. Among men, behavioral inhibition accounted for approximately $9 \%$ of variance in self-concealment.

The relationship between self-concealment and behavioral inhibition was also hypothesized to differ by gender, given that constructs related to behavioral inhibition have been more likely to predict self-concealment for females (Ichiyama et al., 1993). It was expected that this difference would present itself through an interaction. An interaction by gender did not emerge when examining the relationship between self-concealment and behavioral inhibition, failing to meet the specification of Hypothesis 2. However, gender differences in the overall relationship between self-concealment, behavioral inhibition, and behavioral approach emerged when behavioral approach was examined.

Research Question 1 examined the relationship between self-concealment and behavioral approach. Bivariate correlations revealed that Fun Seeking correlated positively with self-concealment for men. This relationship did not emerge for women. Furthermore, behavioral approach did not add significant explanatory value to self-concealment in women. However, for men Fun Seeking and Reward 
Responsiveness added additional explanatory value. Together, behavioral inhibition and behavioral approach accounted for about $21 \%$ of the variance in selfconcealment among men. Fun Seeking accounted for about $9 \%$ of the variance, and Reward Responsiveness contributed inversely to about $4 \%$ of the variance in selfconcealment.

Reward Responsiveness accounted for a small, albeit significant, amount of variance in self-concealment among men. The negative contribution by Reward Responsiveness may reflect positive qualities typically associated with behavioral approach, such as positive affectivity (Carver \& White, 1994). Psychological studies' typical focus on and measurement of pathology may contribute to missing facets of positive health associated with Reward Responsiveness. For example, Reward Responsiveness has been associated with Functional Impulsivity, or the ability to act quickly to capitalize on opportunities (Dawe \& Loxton, 2004). It is interesting to note that Reward Responsiveness did not contribute to selfconcealment among women. Fun Seeking also contributed only to self-concealment in men.

The relationship between self-concealment and Fun Seeking may seem intuitively perplexing. The label "Fun Seeking" connotes a jovial person, and Fun Seeking inversely relates to nervousness (Carver, 2004). However, Fun Seeking also associates with indicators of distress. Fun Seeking significantly correlated with sadness and frustration when a goal, coupled with an award, was not obtained (Carver, 2004). Fun Seeking is associated with bipolar disorder, alcohol problems, and drug problems (Alloy et al., 2008; Johnson et al., 2003). Furthermore, Kahn, 
Jacobson, Gardner, Prescott, and Kendler (2005) found novelty seeking, a construct related to Fun Seeking, strongly associated with externalizing behavior.

The contribution of Fun Seeking to self-concealment in men could be understood as reflecting an externalization of symptoms. Conceptualizing selfconcealment as associated with externalizing behavior fits with the positive link between self-concealment and aggression and delinquency (Frijns et al., 2005). Furthermore, the connection between self-concealment and Fun Seeking in men, but not women, could reflect gender differences in internalizing and externalizing behaviors (James \& Taylor, 2008; Kahn et al., 2005; Kramer, Krueger, \& Hicks, 2008).

Self-concealment might mirror other pathologies that show gender differences in internalizing and externalizing symptoms. For example, for borderline personality disorder, only an internalizing dimension was needed to explain the disorder in women, but both internalizing and externalizing components were needed to explain borderline personality disorder in men (James \& Taylor, 2008). Among adolescents, depression related more to internalizing in females and externalizing in males (Block et al., 1991). This fits with previous self-concealment research, where the internalizing symptoms of depression, anxiety, self-esteem, and shyness contributed to self-concealment in women, but only depression contributed to self-concealment for men (Ichiyama et al., 1993). Had externalizing dimensions been included, they may have predicted self-concealment for men.

Given that neuroticism associates with both internalizing and externalizing behaviors (Kahn et al., 2005; Muris, Meesters, Kanter, Timmerman, 2005), it could 
provide an overarching explanation for self-concealment, as purported by Wismeijer and van Assen (2008). However, neuroticism, by itself, does not appear to encompass Fun Seeking, which independently contributed to self-concealment in men. Neuroticism and impulsivity tend to load on different factors and exhibit nonsignificant or negative correlations (Franken \& Muris, 2006; Kahn et al., 2005). Both a negative affectivity factor and an impulsivity factor may be needed to explain externalizing symptoms, as demonstrated by the contribution of both neuroticism and novelty seeking to externalizing disorders (Kahn et al., 2005). Thus, self-concealment in men could be conceptualized as associated with externalizing behavior, composed of separate impulsivity and negative affectivity dimensions. Still, directionality cannot be determined by these associations. Impulsive behavior, reflective of Fun Seeking, could lead to selfconcealment if spontaneous behavior contributes to problems that are then concealed. In other words, the association between Fun Seeking and selfconcealment may reflect spontaneous persons' need to conceal their impulsive behavior or, in essence, engage in "damage control." Situational stress and consequences from the spontaneous behavior and its repercussions may contribute to feelings of shame, negative affect, and fear of punishment, as indicated by the association between self-concealment and behavioral inhibition and selfconcealment and neuroticism (Wismeijer \& van Assen, 2008).

Persons high in Fun Seeking and behavioral inhibition could, alternatively, have a predisposition toward emotional regulation problems (Donahue \& Grant, 2007; Muris \& Dietvorst, 2006). Accordingly, self-concealment could reflect 
attempts to deal with emotions like anxiety (Lopez et al., 2002). Conceptualizing self-concealers as having emotional regulation problems could parsimoniously explain the emergence of both Fun Seeking and behavioral inhibition as predictors of self-concealment. This conceptualization fits with research suggesting that externalizing and internalizing problems include both negative emotionality and effortful control components (Muris \& Dietvorst, 2006; Valiente et al., 2003). Negative emotionality may parallel the positive contribution of behavioral inhibition and the negative contribution of Reward Responsiveness to the prediction of selfconcealment (Valiente et al., 2003). Effortful control, which involves the ability to voluntarily control attention and behavior, may parallel the contribution of Fun Seeking to self-concealment. Gender then appears to contribute to whether emotional dysregulation symptoms are internalized or externalized. Gender socialization likely contributes to both differences in the manifestation of selfconcealment-related symptoms (e.g., internalizing and externalizing behaviors) and the primary self-concealment process.

Women and men differ in how they are socialized. While men and women can both display elevated levels of self-concealment, their elevations may reflect different concerns and strategies for coping. Women have traditionally been socialized to value relationships. Accordingly, self-concealment in women may be indicative of apprehension about being socially accepted and reflect attempts to withhold information about the self to maintain harmony in relationships (Ichiyama et al., 1993). Jack (1991; Jack \& Dill, 1992) proposed a self-silencing model, where women, due to cultural messages about how to behave, "silence" a part of 
themselves in relationships. This loss of self predisposes them to depression and related symptoms. Research suggests that self-silencing may also hold true for men, as self-concealment has shown to relate to self-silencing in both men and women (Cramer, Gallant, \& Langlois, 2005).

Men have traditionally been socialized to value achievement. Elevated selfconcealment in men may reflect anxiety surrounding being perceived as a failure and secrets may be kept to preserve one's status. Furthermore, messages to be tough and not express emotions indicative of personal weaknesses may further contribute to men concealing negative information about themselves from others. In support, levels of masculinity were found to relate to self-concealment, less self-disclosure, and restrictive emotionality in men (Bruch, 2002; Cramer et al., 2005; Sinn, 1997). Self-concealers, by definition, report experiencing fear and anxiety and may suffer from increased internal conflict when such feelings run counter to their own perceptions of masculinity. This could lead to increased negative symptoms. While gender-role socialization, for both men and women, may meaningfully play a role in self-concealment and related symptoms, gender differences exhibited in this study are in all likelihood a combination of environmental and biologically-based temperamental factors.

This present research does not resolve Kelly's (2002) hypothesis that behavioral inhibition accounts for the connection between self-concealment and negative symptomatology. However, it does provide empirical evidence from which to speculate about its validity. If behavioral inhibition was, indeed, a key link between self-concealment and negative symptomatology, it would have likely 
accounted for a larger portion of variance in self-concealment than the small amount evidenced here. Also, the connection between self-concealment and behavioral inhibition could be due to positive relationships with one or more third variables, such as neuroticism. While an internalizing dimension, like behavioral inhibition, may primarily account for self-concealment in women, results from this study suggest that an externalizing or control dimension may be additionally needed to account for self-concealment in men. However, to ultimately understand the relationship between self-concealment and well-being, symptomatology indices would need to be included in future research.

This study appears to be one of the first to link self-concealment to a facet of behavioral approach. The connection between behavioral approach and selfconcealment in men emerged somewhat unexpectedly, in that the existing literature had not clearly suggested a relationship between the two constructs. Future selfconcealment research would benefit from continuing to look constructs or typologies not previously investigated. For example, future research could examine if there are distinct groups of self-concealers or different ways self-concealment is manifested. For example, self-concealers with higher levels of behavioral approach may use more active forms of deception, like lying, while those higher in behavioral inhibition may be more likely to deceive through omission of information, reflective of avoidance. There may also be differences in emotions associated with selfconcealment, as has been suggested of shame (Gilbert, 1998). All in all, examining self-concealment though multiple theories and perspectives is important in 
considering this multifaceted and complex construct. Limitations of this study may provide additional directions for future research.

An inherent limitation of this study is its correlational design. Although a relationship emerged between self-concealment, behavioral inhibition, and behavioral approach, causation cannot be determined. It was theorized that temperamental characteristics associated with behavioral inhibition precede selfconcealment in a chronological relationship (Kelly, 2002). However, an alternative directional relationship may exist where psychopathology arouses feelings of shame that are then concealed (Tangney et al., 1992). Similarly, impulsivity and spontaneity may lead to concealing consequences of poorly thought out decisions and behavior. Longitudinal designs may be especially beneficial in examining the sequence and directionality of self-concealment. In addition to linear analyses, categorical analyses could assist in understanding issues related to directionality. For example, distinct categories of impulsivity may exist among self-concealers that produce different sequential emergences of self-concealment. Experimental methodologies could also help in understanding issues related to directionality. While short-term manipulations in concealment may not capture the cumulative, long-term effects of self-concealment, different primers could be used to explore if or how self-concealment can be moderated.

A second limitation includes the study's sampling procedure. Snow-ball solicitation combined with a Web medium allowed for a large sample, beyond the typical undergraduate population, to be gathered in an efficient time frame. The web-based survey may have reduced experimenter effects and socially desirable 
responding, often associated with questions of a sensitive nature (Tourangeau \& Yan, 2007). Still, the snow-ball sampling procedure resulted in a self-selected sample with limited information about its parameters, restricting generalizability (Risko, Quilty, \& Oakman, 2006). More demographic information may have been particularly helpful in examining, for example, whether the higher behavioral inhibition exhibited among males related to characteristics specific to this sample. Also, although there appeared to be an adequate number of male participants in this study, it was less than the number of females. This may limit power for discriminating differences in gender. This limitation appears prevalent in many selfconcealment and related studies, particularly those using self-selected samples, where males make up a smaller portion of the sample than females (e.g., Larson \& Chastain, 1990). Also, it is unknown if the males who chose to participate in this study differed significantly from males who chose not to participate (e.g., differences in behavioral inhibition). This sample was primarily Caucasian. Results may vary when examining results of participants from specific cultural, ethnic, discriminated, or underprivileged groups. Finally, the use of a general population sample does not contribute to understanding how self-concealment in the clinical range may differentially relate to behavioral inhibition and behavioral approach. Future self-concealment research would profit from utilizing clinical samples.

A third limitation involves the self-report nature of the SCS and BIS/BAS. It is unknown if or to what degree a portion of the relationship between the SCS and BIS/BAS can be attributed to similar biases within the reporter, rather than to a true relationship between the constructs (Campbell and Fiske, 1959). The self-report 
instruments also prohibit knowledge about the accuracy of participants' responses. Such concerns relate to construct validity, or whether the instrument measures the intended construct (Cronbach \& Meehl, 1955). With regards to the SCS, construct validity issues affect how self-concealment is conceptualized and affect conclusions based on measurement outcomes. Should only persons who score high on the SCS be considered self-concealers? A participant may not endorse certain SCS items if he or she considers the concealed information only private rather than a secret. Also, a repressed person may engage in secret-keeping, but refrain from endorsing items on the SCS related to anxiety. If the above circumstances are reflective of what should be considered self-concealment, then the SCS may be accounting for only a portion of self-concealers.

On the other hand, the SCS may be over-inclusive in its measurement of self-concealment. Scores on the SCS could be superficially inflated by one's tendency to acknowledge pathology, such as with a neurotic personality style. Larson and Chastain (1990) suggested that future research clarify the relationship between self-concealment and negative affectivity. They cautioned that the correlations between various personality variables and health reports could reflect shared variance with neuroticism, in that the same persons who endorse negative factors associated with secrets may endorse somatic complaints not necessarily associated with true disease (Kelly, 2002; Larson \& Chastain, 1990). Additional methods of data collection, including clinical interviews and other qualitative data collection tools, could help to better understand self-concealment and the limitations of the SCS. An objective, or multimodal well-being instrument, in addition to self- 
report, would be necessary to ultimately make conclusions regarding selfconcealment and health. For a complex phenomenon like self-concealment, it is especially important to take into consideration related factors, including shame and social desirability, when examining etiology and expression.

Shame may provide additional ways to explain self-concealment (Pineles et al., 2006). Investigations of the relationship between shame and self-concealment could open the door to identifying different types of self-concealers, such as those whose self-concealment stems from trauma versus personality or temperamental disposition. Self-concealment research could investigate whether the amount of shame surrounding a secret relates to the degree of symptomatology (Kelly \& Yip, 2006). It is also important to consider potential gender differences in the relationship between self-concealment and shame. Given that the selfconcealment/shame study by Pineles et al. (2006) only included females, more information on males' experience of shame and self-concealment may be particularly important.

Research could also examine whether repression tendencies or social desirability biases impact self-concealment. While it is likely that persons who repress and exhibit social desirability also conceal personal information, these persons may not score high on the SCS. For a person to score high on the SCS, the person must be aware of and acknowledge their concealment and surrounding anxiety. Repressors and persons high in social desirability are probably unaware of or would not admit to the behavior and accompanying negative affectivity associated with self-concealment. Thus, measures other than the SCS may be 
necessary to understand the relationship between repression, social desirability, and self-concealment (more broadly defined than with the SCS).

Future research would also benefit from considering whether to control for social-desirability and self-reported anxiety as potential confounding variables, particularly when using measures of symptoms (Garssen, 2007; Weinberger et al., 1979). Paulhus (1984) cautioned that it would be inappropriate to control for variables that encompass intrinsic parts of the construct being measured because it can significantly weaken the factor. He also warned that research should not eliminate potential biases that are believed by the responder to be true because "to purge individual differences in this bias from a personality instrument would be to eliminate a central component of individual differences in personality" (Paulhus, 1984, p. 608). Thus, controlling for constructs like social desirability and repression in self-concealment research focusing on measures of personality should likely be done with care.

More use of categorical analyses would also likely benefit future selfconcealment research. Some relationships may not emerge with linear investigations because combining two distinct groups could mask or obscure findings. There could be, for example, two distinct types of self-concealers differentiated by their level of control (Fun Seeking) and/or negative affectivity. Continued use of hierarchal regression analyses may provide a way to understand how the different constructs contribute to self-concealment, with post hoc analyses using a categorical approach.

All in all, researchers should take time to understand both the empirical and theoretical self-concealment literature before utilizing the SCS. Although the SCS 
does not measure all forms of self-concealment, it does capture something. It is important for self-concealment researchers to understand what the SCS is, in fact, measuring before including it in research and making conclusions based on its results. Although this may seem like an obvious presumption, my literature review enlightened me to misuse and misunderstanding of the SCS, with its inclusion sometimes seemingly based on its namesake alone. With increased caution and preparation taken with its use, more accurate and informative conclusions can be drawn.

A primary purpose of this research was to better understand the relationship between self-concealment and negative symptomatology. Results from this study add to an evolving theory of self-concealment, from one suggesting that concealment in and of itself is harmful to one that focuses on the personality of selfconcealers (Kelly \& Yip, 2006). Kelly’s (2002) hypothesis that self-concealers are unhealthy due to behavioral inhibition was examined. Although limitations of this study do not allow for this question to be fully answered, results did show a positive relationship existed between self-concealment and behavioral inhibition, with behavioral inhibition accounting for a significant, albeit small, amount of variance in self-concealment. Self-concealment in men positively related to Fun Seeking, a facet of behavioral approach associated with impulsivity and spontaneity, which suggests that symptoms associated with self-concealment may manifest differently for men and women.

Research has previously conceptualized self-concealers as primarily exhibiting internalizing symptoms. However, findings from this study help widen 
conceptualizations self-concealers to include externalizing symptoms, particularly among men. A woman who reports concealing negative information about herself may also exhibit internalizing symptoms such as anxiety, depression, low selfesteem, and perfectionism. She also might find herself feeling criticized and withdrawing socially. A man who reports concealing negative information about himself may similarly experience feelings of anxiety and depression. He may additionally find himself exhibiting externalizing behavior, such as not fulfilling school or work obligations, engaging in reckless behaviors, and abusing substances. Still, individual variances beyond gender, such as levels of negative affectivity and effortful control, might further contribute to differences in self-concealment. Future research should continue to focus on such individual differences in self-concealment and associated symptomatology.

Historically self-concealment research focused on the "concealment" aspect of self-concealment. However, newer research highlights the important of focusing on the "self" in self-concealment. The results of this study underscore the importance of examining underlying personality characteristics in order to better understand negative symptoms associated with self-concealment. Rather than being related to the act of secret-keeping, negative symptoms associated with selfconcealment seem suggestive of ineffective emotional and behavioral coping mechanisms within the individual. By recognizing patterns of personality and behavior associated with self-concealment, counselors can more efficiently conceptualize clients, even when particular pieces of the puzzle may be at first 
missing or concealed, and identify those interventions most beneficial for each individual's unique personality and situation.

Most persons experiencing significant psychological distress and seeking psychological assistance deal with issues related to concealment. Although tangible relationship, family, or work issues are typically identified as presenting problems in counseling, deeper issues related to feeling isolated, incompetent, misunderstood, or hopeless are generally concealed from consciousness. When these issues are recognized, necessary information about how to move forward, though likely present at some level of consciousness within the individual, can be hidden from awareness. Accordingly, the process of concealment and disclosure, while seemingly an interpersonal process, is also intrapersonal. Concealment is not only from the other, but from the self. Why am I not happy? What is missing from my life? What do I need to do to improve my well-being? Self-disclosure, as in psychotherapy, can be a first step for improved and continued well-being. Selfdisclosure, by itself, may not be sufficient for complete healing, but can create movement for someone stuck or paralyzed with a particular concern by activating emotional and cognitive changes, even if that change only contributes peeling away one secret so a deeper one can be seen. This study may, correspondingly, serve to peel away a layer of mystery surrounding self-concealment and contribute to a stronger foundation onto which a deeper understanding of self-concealment can be built. 


\section{References}

Alloy, L. B., Abramson, L. Y., Walshaw, P. D., Cogswell, A., Grandin, L. D., Hughes, M. E. . . . Hogan, M. E. (2008). Behavioral Approach System and Behavioral Inhibition System sensitivities and bipolar spectrum disorders: Prospective prediction of bipolar mood episodes. Bipolar Disorders, 10, 310-322.

Bech, P. (1998). Quality of life in the psychiatric patient. London: Mosby-Wolfe.

Beck, A. T., \& Steer, R. A. (1987). Beck Depression Inventory manual. New York: Psychological Corp.

Beck, A. T., \& Steer, R. A. (1990). Beck Anxiety Inventory manual. New York: Psychological Corp.

Block, J. (1965). The challenge of response sets. New York: Appleton-CenturyCrofts.

Block, J., Gjerde, P. F., \& Block, J. H. (1991). Personality antecedents of depressive tendencies in 18-year-olds: A prospective study. Journal of Personality and Social Psychology.

Brennan, K. A., Clark, C. L., \& Shaver, P. R. (1998). Self-report measure of adult attachment. In J. A. Simpson \& W. S. Rholes (Eds.), Attachment theory and close relationships (pp. 46-76). New York: Guilford Press.

Bruch, M. A. (2002). Shyness and toughness: Unique and moderated relations with men's emotional inexpression. Journal of Counseling Psychology, 49, 28-34.

Cameron, J. J., Holmes, J. G., \& Vorauer, J. D. (2009). When self-disclosure goes awry: Negative consequences of revealing personal failures for lower selfesteem individuals. Journal of Experimental Social Psychology, 45, $217-$ 222.

Campbell, D. T., \& Fiske, D. W. (1959). Convergent and discriminant validation by the multi-trait-multimethod matrix. Psychological Bulletin, 56, 81-105.

Carver, C. S. (2004). Negative affects deriving from the behavioral approach system. Emotion, 4, 3-22.

Carver, C. S., \& White, T. L. (1994). Behavioral inhibition, behavioral activation, and affective responses to impending reward and punishment: The BIS/BAS Scales. Journal of Personality and Social Psychology, 67, 319-333.

Caseras, X., Avila, C, \& Torrubia, R. (2003). The measurement of individual 
differences in Behavioral Inhibition and Behavioral Activation Systems: A comparison of personality scales. Personality and Individual Differences, 34, 999-1013.

Cash, T. F., Begley, P. J., McCown, D. A., \& Weise, B. C. (1975). When counselors are heard but not seen: Initial impact of physical attractiveness. Journal of Counseling Psychology, 22, 273-279.

Cepeda-Benito, A., \& Short, P. (1998). Self-concealment, avoidance of psychological services, and perceived likelihood of seeking professional help. Journal of Counseling Psychology, 45, 58-64.

Cheng, T. Y. L., \& Boey, K. W. (2000). Coping, social support, and depressive symptoms of older adults with type II diabetes mellitus. Clinical Gerontologist, 22, 15-30.

Cloninger, C. R. (1987). A systematic method for clinical description and classification of personality variants. Archives of General Psychiatry, 44, 573-588.

Cohen, S., \& Hoberman, H. M. (1983). Positive events and social support as buffers of life change stress. Journal of Applied Social Psychology, 13, 99-125.

Cohen, S., Mermelstein, R., Kamarack, T., \& Hoberman, H. M. (1985). Measuring the functional components of social support. In I. G. Sarason \& B. R. Sarason (Eds.), Social Support: Theory, research, and applications (pp. 7394). The Hague, the Netherlands: Martinus Nijhoff.

Constantine, M. G., Okazaki, S., Utsey, S. O. (2004). Self-concealment, social selfefficacy, acculturative stress, and depression in African, Asian, and Latin American international college students. American Journal of Orthopsychiatry, 74, 230-241.

Costa, P. T., Jr., \& McCrae, R. R. (1992). Revised NEO Personality Inventory and Five-Factor Inventory professional manual. Odessa, FL: Psychological Assessment Resources.

Cramer, K. M. (1999). Psychological antecedents to help-seeking behavior: A reanalysis using path modeling structures. Journal of Counseling Psychology, 46, 381-387.

Cramer, K. M., \& Barry, J. E. (1999). Psychometric properties and confirmatory analysis of the Self-Concealment Scale. Personality and Individual Differences, 27, 629-637.

Cramer, K. M., Gallant, M. D., Langlois, M. W. (2005). Self-silencing and 
depression in women and men: Comparative structural equation models. Personality and Individual Differences, 39, 581-592.

Crocker, J., Luhtanen, R. K., Cooper, M. L., \& Bouvrette, A. (2003). Contingencies of self-worth in college students: Theory and measurement. Journal of Personality and Social Psychology, 85, 894-908.

Cronbach, L. J. \& Meehl, P. E. (1955). Construct validity in psychological tests. Psychological Bulletin, 52, 281-302.

Crowne, D. P. (1979). The experimental study of personality. Hillsdale, NJ: Erlbaum.

Cutrona, C. E., \& Russell, D. W. (1987). The provisions of social relationships and adaptation to stress. Advances in Personal Relationships, 1, 37-67.

Davidson, R. J., Ekman, P., Saron, C. D., Senulis, J. A., \& Friesen, W. V. (1990). Approach-withdrawal and cerebral asymmetry: Emotional expression and brain physiology I. Journal of Personality and Social Psychology, 58, 330341.

Dawe, S., \& Loxton, N. J. (2004). The role of impulsivity in the development of substance use and eating disorders. Neuroscience and Behavioral Reviews, 28, 343-351.

Depue, R. A., \& Collins, P. F. (1999). Neurobiology of the structure of personality: Dopamine, facilitation of incentive motivation, and extraversion. Behavioral and Brain Sciences, 22, 491-517.

Derogatis, L. R. (1993). Brief Symptom Inventory (BSI); Administration, scoring, and procedures manual ( ${ }^{\text {rd }}$ ed.). Minneapolis, $\mathrm{MN}$ : National Computer Systems, Inc.

Derogatis, L. R., Lipman, R. S., Rickels, K., Uhlenhuth, E. H., \& Covi, L. (1974). The Hopkins Symptom Checklist (HSCL): A self-report symptom inventory. Behavioral Science, 19, 1-15.

Derogatis, L. R., \& Melisaratos, N. (1983). The Brief Symptom Inventory: An introductory report. Psychological Medicine, 13, 595-605.

DiBartolo, P. M., Frost, R. O., Chang, P., LaSota, M., \& Grills, A. E. (2004). Shedding light on the relationship between personal standards and psychopathology: The case for contingent self-worth. Journal of RationalEmotive and Cognitive Behavior Therapy, 22, 241-254.

DiBartolo, P. M., Li, C. Y., \& Frost, R. O. (2008). How do the dimensions of 
relate to mental health? Cognitive Therapy Research, 32, 401-417.

Dibble, S. L., \& Swanson, J. M. (2000). Gender differences for the predictors of depression in young adults with genital herpes. Public Health Nursing, 17, 187-194.

Donahue, C. B., \& Grant, J. E. (2007). Stress and impulsive behaviors. In M. al'Absi (Ed.), Stress and addiction: Biological and psychological mechanisms (pp. 191-210). San Diego, CA: Elsevier Academic Press.

Doster, J. A. (1975). Individual differences affecting interviewee expectancies and perceptions of self-disclosure. Journal of Counseling Psychology, 22, 192198.

Eysenck, H. J. (1947). Dimensions of personality. London: Routledge \& Kegan Paul.

Eysenck, H. J., \& Eysenck, S. B. G. (1975). Manual of the Eysenck Personality Questionnaire. San Diego, CA: Educational and Testing Service.

Eysenck, H. J., \& Eysenck, M. W. (1985). Personality and individual differences: A natural sciences approach. New York: Plenum.

Finkenauer, C., Engels, R. C. M. E., \& Meeus, W. (2002). Keeping secrets from parents: Advantages and disadvantages of secrecy in adolescence. Journal of Youth and Adolescence, 31, 123-136.

Fischer, E. H., \& Turner, J. L. (1970). Orientations to seeking professional help: Development and research utility of an attitude scale. Journal of Consulting and Clinical Psychology, 35, 79-90.

Fowles, D. C. (1980). The three arousal model: implications of Gray's Two Factor Learning Theory for heart rate, electrodermal activity and psychopathology. Psychophysiology, 17, 87-104.

Fowles, D. C. (1987). Application of a behavioral theory of motivation to the concepts of anxiety and impulsivity. Journal of Research in Personality, 21, 417-435.

Fowles, D. C. (1988). Psychophysiology and psychopathology: A motivational approach. Psychophysiology, 25, 373-391.

Franken, I. H. A., \& Muris, P. (2006). Gray's impulsivity dimension: A distinction between Reward Sensitivity versus Rash Impulsiveness. Personality and Individual Differences, 40, 1337-1347. 
Frijns, T., Finkenauer, C., Vermulst, A. A., \& Engels, R. C. M. E. (2005). Keeping secrets from parents: Longitudinal associations of secrecy in adolescence. Journal of Youth and Adolescence, 34, 137-148.

Frost, R. O., Marten, P., Lahart, C., \& Rosenblate, R. (1990). The dimensions of perfectionism. Cognitive Therapy and Research, 14, 449-468.

Frost, D. M., Parsons, J. T., Nanin, J. E. (2007). Stigma, concealment and symptoms of depression as explanations for sexually transmitted infections among gay men. Journal of Health Psychology, 12, 636-640.

Garssen, B. (2007). Repression: Finding our way in the maze of concepts. Journal of Behavioral Medicine, 30, 471-481.

Green, D. E., Walkey, F. H., McCormick, I. A., \& Taylor, A. J. (1988). Development and evaluation of a 21-item version of the Hopkins Symptom Checklist with New Zealand and United States respondents. Australian Journal of Psychology, 40, 61-70.

Giese-Davis, J., \& Spiegel, D. (2001). Suppression, repressive-defensiveness, restraint, and distress in metastatic breast cancer: Separable or inseparable constructs. Journal of Personality, 69, 417-449.

Gilbert, P. (1998). What is shame? Some core issues and controversies. In P. Gilbert \& B. Andrews (Eds.), Shame: Interpersonal behavior, psychopathology, and culture (pp. 3-38). Oxford: Oxford University Press.

Gim, R. H., Atkinson, D. R., \& Whiteley, S. (1990). Asian-American acculturation, severity of concerns, and willingness to see a counselor. Journal of Counseling Psychology, 37, 281-285.

Gomez, R., Cooper, A., \& Gomez, A. (2005). An item response theory analysis of the Carver and White (1994) BIS/BAS Scales. Personality and Individual Differences, 39, 1093-1103.

Gomez, R., \& Gomez, A. (2005). Convergent, discriminant and concurrent validities of measures of the behavioural approach and behavioral inhibition systems: Confirmatory factor analytic approach. Personality and Individual Differences, 38, 87-102.

Gough, H. G. (1956). Manual for the California Psychological Inventory. Palo Alto, CA: Consulting Psychologists Press.

Gough, H. G. (1960). Theory and measurement of socialization. Journal of Consulting Psychology, 24, 23-30. 
Gould, J. R., Prentice, N. M., \& Ainslie, R. C. (1996). The splitting index: Construction of a scale measuring the defense mechanism of splitting. Journal of Personality Assessment, 66, 414-430.

Gray, J. A. (1970). The psychophysiological basis of introversion-extraversion. Behaviour Research and Therapy, 8, 249-266.

Gray, J. A. (1987). The neuropsychology of emotion and personality. In S. M. Stahl, S. D. Iversen \& E. C. Goodman (Eds.), Cognitive neurochemistry (pp. 171190). Oxford: Oxford University Press.

Gray, J. A. (1991). Neural systems, emotion, and personality. In J. Madden (Ed.), Neurobiology of learning, emotion, and affect (pp. 273-306). New York: Raven Press.

Grills, C., \& Longshore, D. (1996). Africentrism: Psychometric analyses of a selfreport measure. Journal of Black Psychology, 22, 86-106.

Heubeck, B. G., Wilkinson, R. B., \& Cologon, J. (1998). A second look at Carver and White's (1994) BIS/BAS scales. Personality and Individual Differences, 25, 785-800.

Higgins, E. T. (1987). Self-discrepancy: A theory relating self and affect. Psychological Review, 94, 319-340.

Higgins, E. T., Shah, J., 7 Friedman, R. (1997). Emotional responses to goal attainment: Strength of regulatory focus as moderator. Journal of Personality and Social Psychology, 72, 515-525.

Ichiyama, M. A., Colbert, D., Laramore, H., Heim, M., Carone, K., \& Schmidt, J. (1993). Self-concealment and correlates of adjustment in college students. Journal of College Student Psychotherapy, 7, 55-68.

Jack, D. C. (1991). Silencing the self: Women and depression. Cambridge: Harvard University Press.

Jack, D. C., \& Dill, D. (1992). The Silencing Self-Scale. Psychology of Women Quarterly, 16. 97-106.

James, L. M., \& Taylor, J. (2008). Revisiting the structure of mental disorders: Borderline personality disorder and the internalizing/externalizing spectra. British Journal of Clinical Psychology, 47, 361-380.

Johnson, S. L., Turner, R. J., \& Iwata, N. (2003). BIS/BAS levels and psychiatric disorder: An epidemiological study. Journal of Psychopathology and Behavioral Assessment, 25, 25-36. 
Jones, W. H., \& Briggs, S. R. (1986). Manual for the social reticence scale: A measure of shyness. Palo Alto, CA: Consulting Psychologists Press.

Jorm, A. F., Christensen, H., Henderson, A. S., Jacomb, P. A., Korten, A. E., \& Rodgers, B. (1999). Using the BIS/BAS scales to measure behavioural inhibition and behavioural activation: Factor structure, validity and norms in a large community sample. Personality and Individual Differences, 26, 4958.

Kagan, J. (1997). Temperament and the reactions to the unfamiliar. Child Development, 68, 139-143.

Kahn, J. H., \& Hessling, R. M. (2001). Measuring the tendency to conceal versus disclose psychological distress. Journal of Social and Clinical Psychology, 20, 41-65.

Kahn, A. A., Jacobson, K. C., Gardner, C. O., Prescott, C. A., \& Kendler, K. S. (2005). Personality and comorbidity of common psychiatric disorders. British Journal of Psychiatry, 186, 190-196.

Kahn, J. H., Lamb, D. H., Champion, C. D., Eberle, J. A., \& Schoen, K. A. (2002). Disclosing versus concealing distressing information: linking self-reported tendencies to situational behavior. Journal of Research in Personality, 36, 531-538.

Kandel, D., \& Davies, M. (1982). Epidemiology of depressive mood in adolescents. Archives of General Psychiatry, 39, 1205-1212.

Kashdan, T. B., \& Roberts, J. E. (2006). Affective outcomes in superficial and intimate interactions: Roles of social anxiety and curiosity. Journal of Research in Personality, 40, 140-167.

Kawamura, K. Y., \& Frost, R. O. (2004). Self-concealment as a mediator in the relationship between perfectionism and psychological distress. Cognitive Therapy and Research, 28, 183-191.

Kawano, K. (2000). Correlational analysis among Japanese Self-concealment Scale, Kida's Stimulus-Seeking Scale and self-reported physical symptoms. The Japanese Journal of Experimental Social Psychology, 40, 115-121.

Kelly, A. E. (1998). Clients' secret keeping in outpatient therapy. Journal of Counseling Psychology, 45, 50-57.

Kelly, A. E. (2002). The psychology of secrets. New York: Plenum. 
Kelly, A. E., \& Archter, J. A. (1995) Self-concealment and attitudes toward counseling in university students. Journal of Counseling Psychology, 42, 4046.

Kelly, A. E., \& Yip, J. J. (2006). Is keeping a secret or being a secretive person linked to psychological symptoms? Journal of Personality, 75, 1349-1369.

Kernberg, O. (1976). Object relations theory and clinical psychoanalysis. New York: Jason Aronson.

Kessler, R. C. (1994). The National Comorbidity Survey in the United States, International Review of Psychiatry, 6, 365-376.

King, L. A., Emmons, R. A., Woodley, S. (1992). The structure of inhibition. Journal of Research in Personality, 26, 85-102.

Komiya, N., Good, G. E., \& Sherrold, N. B. (2000). Emotional openness as a predictor of college students' attitudes toward seeking psychological help. Journal of Counseling Psychology, 47, 138-143.

Kramer, M. D., Krueger, R. F., \& Hicks, B. M. (2008). The role of internalizing and externalizing liability factors in accounting for gender differences in the prevalence of common psychopathological syndromes. Psychological Medicine, 38, 51-61.

Kushner, M. G., \& Sher, K. J. (1989). Fears of psychological treatment and its relation to mental health service avoidance. Professional Psychology: Research and Practice, 20, 251-257.

Larsen, R. J., \& Augustine, A. A. (2008). Basic personality dispositions related to approach and avoidance: Extraversion/neuroticism, BAS/BIS, and positive and negative affectivity. In Andrew J. Elliot (Ed.), Handbook of approach and avoidance motivation (pp. 151-164). New York: Psychology Press.

Larson, D. G., \& Chastain, R. L. (1990). Self-concealment: Conceptualization, measurement, and health implications. Journal of Social and Clinical Psychology, 9, 43-455.

Leech, N. L. (2007). Cramer's model of willingness to seek counseling: A structural equation for counseling students. The Journal of Psychology, 14, 435-445.

Leone, L., Perugini, M., Bagozzi, R. P., Pierro, A., \& Mannetti, L. (2001). Construct validity and generalizability of the Carver-White Behavioural Inhibition System/Behavioral Activation System Scales. European Journal of Personality, 15, 373-390. 
Liao, H., Rounds, J., \& Klein, A. G. (2005). A test of Cramer's (1999) help-seeking model and acculturation effects with Asian and Asian American college students. Journal of Counseling Psychology, 52, 400-411.

Lopez, F. G. (2001). Adult attachment orientations, self-other boundary regulation, and splitting tendencies in a college sample. Journal of Counseling Psychology, 48, 440-446.

Lopez, F. G., Mitchell, P., \& Gormley, B. (2002). Adult attachment orientations and college student distress: Test of a meditational model. Journal of Counseling Psychology, 49, 460-467.

Lovibond, S. H., \& Lovibond, P. F. (1995a). Manual for the Depression and Anxiety Stress Scales. Sydney: The Psychology Foundation of Australia.

Lovibond, P. F., \& Lovibond, S. H. (1995b). The structure of negative emotional states: Comparison of the Depression Anxiety Stress Scale (DASS) with the Beck Depression and Anxiety Inventories. Behaviour Research and Therapy, 33, 335-343.

MacAndrew, C., \& Steele, T. (1991). Gray's behavioral inhibition system: A psychometric evaluation. Personality and Individual Differences, 12, 157171.

MacDonald, J., \& Morley, I. (2001). Shame and non-disclosure: A study of the emotional isolation of people referred to psychotherapy. British Journal of Medical Psychology, 74, 1-21.

Maij-de Meij, A. M., Kelderman, H., \& van der Flier, H. (2005). Latent-trait latentclass analysis of self-disclosure in the work environment. Multivariate Behavioral Research, 40, 435-459.

Mellinger, G. D., Balter, M. B., Manheimer, D. I., Cisin, I. H., \& Parry, H. J. (1978). Psychic distress, life crisis, and use of psychotherapeutic medications. Archives of General Psychiatry, 35, 1045-1052.

Miller, L. C., Berg, J. H., \& Archer, R. L. (1983). Openers: Individuals who elicit intimate self-disclosure. Journal of Personality and Social Psychology, 44, 1234-1244.

Millham, J., \& Kellogg, R. W. (1980). Need for social approval: Impression management or self-deception? Journal of Research in Personality, 14, 445457.

Mowen, J. C. (2000). The 3M model of motivation and personality: Theory and applications to consumer behavior. Boston, MA: Kluwer Academic. 
Muris, P., \& Dietvorst, R. (2006). Underlying personality characteristics of behavioral inhibition in children. Child Psychiatry Human Development, 36, 437-445.

Muris, P., \& Meesters, C. (2002). Attachment, behavioral inhibition, and anxiety disorders symptoms in normal adolescents. Journal of Psychopathology and Behavioral Assessment, 24, 97-105.

Muris, P., Meesters, C., Kanter, E., Timmerman, P. E. (2005). Behavioural inhibition and behavioural activation system scales for children: Relationships with Eysenck's personality traits and psychopathological symptoms. Personality and Individual Differences, 38, 831-841.

Nigg, J. T. (2000). On Inhibition/Disinhibition in developmental psychopathology: Views from cognitive and personality psychology and a working inhibition taxonomy. Psychological Bulletin, 126, 229-246.

Omori, M. (2007). Japanese college students' attitudes toward professional psychological services: The role of cultural self-construal and selfconcealment. Psychological Reports, 100, 387-399.

Patterson, G. R., \& Capaldi, D. M. (1990). A meditational model for boys' depressed mood. In J. Rolf, A. S. Masten, D. Cicchetti, K. H. Neuchterlin, \& S. Weintraub (Eds.), Risk and protective factors in the development of psychopathology (pp. 141-163). New York: Cambridge University Press.

Paulhus, D. L. (1984). Two-component models of socially desirable responding. Journal of Personality and Social Psychology, 46, 598-609.

Paulhus, D. L. (2002). Socially desirable responding: the evolution of a construct. In Henry I. Braun, Douglas H. Jackson, \& David E. Wiley (Eds.), The role of constructs in psychological and educational memberships (pp. 49-69). Mahwah, NJ: Lawrence Erlbaum.

Paulhus, D. L., \& John, O. P. (1998). Egoistic and moralistic biases in selfperception: The interplay of self-deceptive styles with basic traits and motives. Journal of Personality, 66, 1025-1060.

Pennebaker, J. W., \& Beall, S. K. (1986). Confronting a traumatic event: Toward an understanding of inhibition and disease. Journal of Abnormal Psychology, 95, 274-281.

Pennebaker, J. W., \& Chung, C. K. (2007). Expressive writing, emotional upheavals, and health. In H. S. Friedman \& R. C. Silver (Eds.), Foundations of health psychology (pp. 263-284). New York: Oxford University Press. 
Pennebaker, J. W., \& O'Heeron, R. C. (1984). Confiding in others and illness rate among spouses of suicide and accidental-death victims. Journal of Abnormal Psychology, 4, 473-476.

Pennebaker, J. W., \& Susman, J. R. (1988). Disclosure of traumas and psychosomatic processes. Social Science and Medicine, 26, 327-332.

Pickering, A. D. (1997). The conceptual nervous system and personality: From Pavlov to neural networks. European Psychologist, 2, 139-163.

Pickering, A. D., Corr, P. J., \& Gray, J. A. (1999). Interactions and reinforcement sensitivity theory: A theoretical analysis of Rusting and Larsen (1997). Personality and Individual Differences, 26, 357-365.

Pineles, S. L., Street, A. E., Koenen, K. C. (2006). The differential relationships of shame-proneness and guilt-proneness to psychological and somatization symptoms. Journal of Social and Clinical Psychology, 25, 688-704.

Potoczniak, D. J., Aldea, M. A., \& DeBlaere, C. (2007). Ego identity, social anxiety, social support, and self-concealment in lesbian, gay, and bisexual individuals. Journal of Counseling Psychology, 54, 447-457.

Priess, H. A., Lindberg, S. M., \& Hyde, J. S. (2009). Adolescent gender-role identity and mental health: gender intensification revisited. Child Development, 80, 1531-1544.

Radloff, L. S. (1977). The CES-D Scale: A self-report depression scale for research in the general population. Applied Psychological Measurement, 1, 385-401.

Reis, J. (1988). A factorial analysis of a compound measure of social support. Journal of Clinical Psychology, 44, 876-890.

Reynolds, W. M. (1982). Development of reliable and valid short forms of the Marlowe-Crowne Social Desirability Scale. Journal of Clinical Psychology, $38,119-125$.

Risko, E. F., Quilty, L. C., \& Oakman, J. M. (2006). Socially desirable responding on the Web: Investigating the candor hypothesis. Journal of Personality Assessment, 87, 269-276.

Ritz, T., \& Dahme, B. (1994). Rationalitalitat/Emotionale Defensivitat und SichVerschlienBen: Zwei Konzepte des defensive Coping und ihre Messung [Rationality/Emotional Defensivenss and Self-Concealment: Two concepts of defensive coping and their measurement]. Arbeiten aus dem 
Psychologischen Institut III der Universitat Hamburg. University of Hamburg.

Ritz, T., \& Dahme, B. (1996). Repression, self-concealment and rationality/emotional defensiveness: The correspondence between three questionnaire measures of defensive coping. Personality and Individual Differences, 20, 95-102.

Rosenberg, M. (1979). Conceiving the self. New York: Basic Books.

Sackeim, H. A., \& Gur, R. C. (1978). Self-deception, self-confrontation and consciousness. In G. E. Schwartz \& D. Davidson (Eds.), Consciousness and self-regulation, advances in research and theory. (Vol. 2). New York: Plenum Press.

Sackeim, H. A., \& Gur, R. C. (1979). Self-deception, other-deception, and selfreported psychopathology. Journal of Consulting and Clinical Psychology, 47, 213-215.

Sandhu, D. S., \& Asrabadi, B. R. (1994). Development of an acculturative stress scale for international students: Preliminary findings. Psychological Reports, $75,435-448$.

Scheier, M. F., \& Carver, C. S. (1985). Optimism, coping, and health: Assessment implications of generalized outcome expectancies. Health Psychology, 4, 219-247.

Sherer, M., \& Adams, C. H. (1983). Construct validation of the Self-Efficacy Scale. Psychological Reports, 53, 899-902.

Sikkel, D. (1980). Een verkorting van de VOEG-schaal. [An abbreviated version of the VOEG-scale]. Sociaal Cultureel Kwartaalbericht, 2, 22-26.

Sinn, J. S. (1997). The predictive and discriminant validity of masculine ideology. Journal of Research in Personality, 31, 117-135.

Smetana, J. G., Metzger, A., Gettman, D. C., \& Campione-Barr, N. (2006). Disclosure and secrecy in adolescent-parent relationships. Child Development, 77, 201-217.

Smillie, L. D., \& Jackson, C. J. (2006). Functional Impulsivity and Reinforcement Sensitivity Theory. Journal of Personality, 74, 47-83.

Smillie, L. D., Jackson, C. J., \& Dalgleish, L. I. (2006). Conceptual distinctions among Carver and White's (1994) BAS scales: A reward-reactivity versus trait impulsivity perspective. Personality and Individual Differences, 40, 1039-1050. 
Steinberg, L., \& Silverberg, S. B. (1986). The vicissitudes of autonomy in early adolescence. Child Development, 57, 841-851.

Stevens, J. (1999). Intermediate statistics: A modern approach ( $2^{\text {nd }}$ ed.). Mahwah, NJ: Lawrence Earlbaum.

Stice, E., Telch, C. F., \& Rizvi, S. L. (2000). Development and validation of the Eating Disorder Diagnostic Scale: A brief self-report measure of anorexia, bulimia, and binge-eating disorder, Psychological Assessment, 12, 123-131.

Tangney, J. P., Wagner, P. E., \& Gramzow, R. (1989). The Test of Self-conscious Affect. Fairfax, VA: George Mason University.

Tangney, J. P., Wagner, P. E., \& Gramzow, R. (1992). Proneness to shame, proneness to guilt, and psychopathology. Journal of Abnormal Psychology, 101, 469-478.

Taylor, J. A. (1953). A personality scale for manifest anxiety. Journal of Abnormal and Social Psychology, 48, 285-290.

Torrubia, R., \& Tobena, A. (1984). A scale for the assessment of "susceptibility to punishment" as a measure of anxiety: Preliminary results. Personality and Individual Differences, 5, 371-375.

Tourangeau, R., \& Yan, T. (2007). Sensitive questions in surveys. Psychological Bulletin, 133, 859-883.

Valiente, C., Eisenberg, N., Smith, C. L., Reiser, M., Fabes, R. A., Losoya, S. . . Murphy, B. C. (2003). The relations of effortful control and reactive control to children's externalizing problems: A longitudinal assessment. Journal of Personality, 71, 1172-1196.

Vaux, A. (1985). Factor structure of the Network Orientation Scale. Psychological Reports, 57, 1181-1182.

Wallace, B. C., \& Constantine, M. G. (2005). Africentric cultural values, psychological help-seeking attitudes, and self-concealment in African American college students. Journal of Black Psychology, 31, 369-385.

Warren, C., \& Laslett, B. (1977). Privacy and secrecy: A conceptual comparison. Journal of Social Issues, 33, 43-51.

Watson, D., \& Clark, L. A. (1993). Behavioral disinhibition versus constraint: A dispositional perspective. In D. M. Wegner \& J. W. Pennebaker (Eds.), Handbook of mental control (pp. 506-527). Englewood Cliffs, NJ: PrenticeHall. 
Watson, D., Clark, L. A., \& Tellegen, A. (1988). Development and validation of brief measures of positive and negative affect: The PANAS scales. Journal of Personality and Social Psychology, 54, 1063-1070.

Watson, D., \& Friend, R. (1969). Measurement of social-evaluative anxiety. Journal of Consulting and Clinical Psychology, 33, 448-457.

Weinberger, D. A. (1990). The construct validity of the repressive-defensive coping style. In J. L. Singer (Ed.), Repression and dissociation: Defense mechanisms and personality styles (pp. 337-386). Chicago: Univ. of Chicago Press.

Weinberger, D. A., \& Schwartz, G. E. (1990). Distress and restraint as superordinate dimensions of self-reported adjustment: A typological perspective. Journal of Personality, 58, 381-417.

Weinberger, D. A., Schwartz, G. E., \& Davidson, R. J. (1979). Low-anxious, highanxious, and repressive coping styles: Psychometric patterns and behavioral and physiological responses to stress. Journal of Abnormal Psychology, 88, 369-380.

Wiggins, J. S. (1964). Convergences among stylistic response measures from objective personality tests. Educational and Psychological Measurement, 24, 419-427.

Wilcox, B. L. (1981). Social support, life stress, and psychological adjustment: A test of the buffering hypothesis. American Journal of Community Psychology, 9, 371-386.

Wismeijer, A., \& van Assen, M. (2008). Do neuroticism and extraversion explain the negative association between self-concealment and subjective wellbeing? Personality and Individual Differences, 45, 345-349.

Yoo, S., Goh, M., \& Yoon, E. (2005). Psychological and cultural influences on Koreans' help-seeking attitudes. Journal of Mental Health Counseling, 27, 266-281.

Yukawa, S., Tokuda, H., \& Sato, J. (2007). Attachment style, self-concealment, and interpersonal distance among Japanese undergraduates. Perceptual and Motor Skills, 104, 1255-1261.

Zimet, G. D., Dahlem, N. W., Zimet, S. D., \& Farley, G. K. (1988). The Multidimensional Scale of Perceived Social Support. Journal of Personality Assessment, 52, 30-41. 
Zuckerman, M., Kuhlman, D. M., Joireman, J., Teta, P., \& Kraft, M. (1993). A comparison of three structural models for personality: The Big Three, the Big Five, and the Alternative Five. Journal of Personality and Social Psychology, 65, 757-768. 


\section{Appendix A}

The Self-Concealment Scale (SCS)

\begin{tabular}{|c|c|c|c|c|c|c|c|}
\hline & \multicolumn{2}{|c|}{$\begin{array}{l}1 \\
\text { Strongly } \\
\text { Disagree }\end{array}$} & \multicolumn{2}{|c|}{$\begin{array}{l}2 \\
\text { Disagree }\end{array}$} & $\begin{array}{l}3 \\
\text { Neutral }\end{array}$ & $\begin{array}{l}4 \\
\text { Agree }\end{array}$ & $\begin{array}{l}5 \\
\text { Strongly } \\
\text { Agree }\end{array}$ \\
\hline 1 & 2 & 3 & 4 & 5 & \multicolumn{3}{|c|}{$\begin{array}{l}\text { I have an important secret that I haven't shared } \\
\text { with anyone. }\end{array}$} \\
\hline 1 & 2 & 3 & 4 & 5 & \multicolumn{3}{|c|}{$\begin{array}{l}\text { If I shared all my secrets with my friends, } \\
\text { they'd like me less. }\end{array}$} \\
\hline 1 & 2 & 3 & 4 & 5 & \multicolumn{3}{|c|}{$\begin{array}{l}\text { There are lots of things about me that I keep to } \\
\text { myself. }\end{array}$} \\
\hline 1 & 2 & 3 & 4 & 5 & \multicolumn{3}{|c|}{ Some of my secrets have really tormented me. } \\
\hline 1 & 2 & 3 & 4 & 5 & \multicolumn{3}{|c|}{$\begin{array}{l}\text { When something bad happens to me, I tend to } \\
\text { keep it to myself. }\end{array}$} \\
\hline 1 & 2 & 3 & 4 & 5 & \multicolumn{3}{|c|}{$\begin{array}{l}\text { I'm often afraid I'll reveal something I don't } \\
\text { want to. }\end{array}$} \\
\hline 1 & 2 & 3 & 4 & 5 & \multicolumn{3}{|c|}{$\begin{array}{l}\text { Telling a secret often backfires and I wish I } \\
\text { hadn't told it. }\end{array}$} \\
\hline 1 & 2 & 3 & 4 & 5 & \multicolumn{3}{|c|}{$\begin{array}{l}\text { I have a secret that is so private I would lie if } \\
\text { anybody asked me about it. }\end{array}$} \\
\hline 1 & 3 & 3 & 4 & 5 & \multicolumn{3}{|c|}{$\begin{array}{l}\text { My secrets are too embarrassing to share with } \\
\text { others. }\end{array}$} \\
\hline 1 & 2 & 3 & 4 & 5 & \multicolumn{3}{|c|}{$\begin{array}{l}\text { I have negative thoughts about myself that I } \\
\text { never share with anyone. }\end{array}$} \\
\hline
\end{tabular}

Larson, D. G., \& Chastain, R. L. (1990). Self-concealment: Conceptualization, measurement, and health implications. Journal of Social and Clinical Psychology, 9, 439-455. 


\section{Appendix B}

Self-Concealment Scale factors identified by Cramer and Barry (1999)

\section{Factor 1: Keeping Secrets}

1. I have an important secret that I haven't shared with anyone.

2. If I shared all my secrets with my friends, they'd like me less.

4. Some of my secrets have really tormented me.

8. I have a secret that is so private I would lie if anybody asked me about it.

9. My secrets are too embarrassing to share with others.

\section{Factor 2: Personal Concealment}

3. There are lots of things about me that I keep to myself.

5. When something bad happens to me, I tend to keep it to myself.

6. I'm often afraid I'll reveal something I don't want to.

7. Telling a secret often backfires and I wish I hadn't told it.

10. I have negative thoughts about myself that I never share with anyone.

Cramer, K. M. \& Barry, J. E. (1999). Psychometric properties and confirmatory analysis of the Self-Concealment Scale. Personality and Individual Differences, 27, 629-637.

Larson, D. G., \& Chastain, R. L. (1990). Self-concealment: Conceptualization, measurement, and health implications. Journal of Social and Clinical Psychology, 9, 439-455. 


\section{Appendix C}

The Behavioral Inhibition System/Behavioral Activation System (BIS/BAS) Scales

Indicate your agreement with each statement. (Response choices 1 though 4, $1=$ Strong agreement; $4=$ Strong disagreement).

1. I'm always willing to try something new if I think it will be fun.

2. When I'm doing well at something, I love to keep at it.

3. I feel pretty worried or upset when I think or know somebody is angry at me.

4. I feel worried when I think I have done poorly at something.

5. If I think something unpleasant is going to happen I usually get pretty "worked up."

6. If I see a chance to get something I want, I move on it right away.

7. It would excite me to win a contest.

8. I have very few fears compared to my friends.

9. I crave excitement and new sensations.

10. Even if something bad is about to happen to me, I rarely experience fear or nervousness.

11. I go out of my way to get things I want.

12. I worry about making mistakes.

13. When I go after something I use a "no holds barred" approach.

14. I often act on the spur of the moment.

15. When I see a good opportunity for something I like, I get excited right away.

16. When good things happen to me, it affects me strongly.

17. I will often do things for no other reason than that they might be fun.

18. When I want something, I usually go all-out to get it.

19. Criticism or scolding hurts me quite a lot.

20. When I get something I want I feel excited and energized.

Carver, C. S. \& White, T. L. (1994). Behavioral inhibition, behavioral activation, and affective responses to impending reward and punishment: The BIS/BAS Scales. Journal of Personality and Social Psychology, 67(2), 319-333. 


\section{Appendix D}

The BIS/BAS (Carver \& White, 1994) categorized by subscale

\section{Behavioral Inhibition System Scale}

3. I feel pretty worried or upset when I think or know somebody is angry at me.

4. I feel worried when I think I have done poorly at something.

5. If I think something unpleasant is going to happen I usually get pretty "worked up."

8. I have very few fears compared to my friends.

10. Even if something bad is about to happen to me, I rarely experience fear or nervousness.

12. I worry about making mistakes.

19. Criticism or scolding hurts me quite a lot.

Behavioral Activation System-Reward Responsiveness Scale

2. When I'm doing well at something, I love to keep at it.

7. It would excite me to win a contest.

15. When I see a good opportunity for something I like, I get excited right away.

16. When good things happen to me, it affects me strongly.

20. When I get something I want I feel excited and energized.

Behavioral Activation System-Drive Scale

6. If I see a chance to get something I want, I move on it right away.

11. I go out of my way to get things I want.

13. When I go after something I use a "no holds barred" approach.

18. When I want something, I usually go all-out to get it.

Behavioral Activation System-Fun Seeking Scale

1. I'm always willing to try something new if I think it will be fun.

9. I crave excitement and new sensations.

17. I will often do things for no other reason than that they might be fun.

14. I often act on the spur of the moment.

Carver, C. S. \& White, T. L. (1994). Behavioral inhibition, behavioral activation, and affective responses to impending reward and punishment: The BIS/BAS Scales. Journal of Personality and Social Psychology, 67(2), 319-333. 


\section{Appendix E}

\section{INFORMATION SHEET FOR CONSENT TO PARTICIPATE IN A RESEARCH} STUDY

My name is Hayley Ornstein, and I am a graduate student in the Educational Psychology Department at the University of Oklahoma. I am requesting that you volunteer to participate in a research study about personality characteristics. If you are between the ages of 18 and 64 years old, you are eligible to participate in this study. Please read this information sheet. You can contact me with any questions that you have before agreeing to take part in this study.

PURPOSE OF THE RESEARCH STUDY: The purpose of this study is to find out more about how concealing information relates to different personality traits.

PROCEDURES: If you agree to be in this study, you will be presented with a survey and asked to rate the degree to which you agree with various statements about your feelings and behaviors. Your responses will be anonymous. In other words, your responses will not be linked to your identity.

RISKS AND BENEFITS OF BEING IN THE STUDY: There are little risks associated with participating in this study. The stress brought about by completing this survey is likely no greater than the stress you encounter in your everyday life. Still, some of the questions ask you about negative feelings. It is possible that you may find these questions stressful or prefer not to respond. In such cases, you have the option of skipping the item or exiting the survey completely. There will be no penalty for doing so. However, the most knowledge will be gained from your responses when you answer the items completely and truthfully. You will likely not gain any direct benefits from participating in the study.

COMPENSATION: You will not be compensated for your time and participation in this study. However, upon submitting the survey you will have the option of entering a drawing for a $\$ 75 \mathrm{Wal}-\mathrm{Mart}$ gift certificate. If you choose to enter the drawing, you will need to provide your contact information, but it will not be connected to your survey responses.

VOLUNTARY NATURE OF THE STUDY: Participation in this study is voluntary. Your decision whether or not to participate will not result in penalty. If you decide to participate, you are free not to answer any question or discontinue participation at any time without penalty.

LENGTH OF PARTICIPATION: The survey is expected to take about 10 minutes to complete.

CONFIDENTIALITY: This study is anonymous. In published reports, there will be no information included that will make it possible to identify you as a research 
participant.

CONTACTS AND QUESTIONS: If you have concerns or complaints about the research, please contact the researcher, Hayley Ornstein, at hayleyc@ou.edu or (405) 388-4486. Her advisor Cal Stoltenberg, Ph.D. can also be reached at cstoltenberg@ou.edu or (405) 325-5974. If you have any questions, concerns, or complaints about the research and wish to talk to someone other than the individuals on the research team, or if you cannot reach the research team, you may contact the University of Oklahoma - Norman Campus Institutional Review Board (OU-NC IRB) at (405) 325-8110 or irb@ou.edu.

If you experience emotional distress from this study, psychological treatment is available. However, you or your insurance company will be expected to pay the usual charge from this treatment. The University of Oklahoma Norman Campus has set aside no funds to compensate you in the event of injury.

You should print out and keep a copy of this information sheet for your records.

By clicking "I agree", you are agreeing to participate in this study. 
Table 1

Internal reliability coefficients and mean scores and standard deviations scores for males and females.

\begin{tabular}{lccccc}
\hline & & \multicolumn{2}{c}{ Male } & \multicolumn{2}{c}{ Female } \\
& Alpha & Mean & $\begin{array}{c}\text { Std. } \\
\text { Deviation }\end{array}$ & Mean & $\begin{array}{c}\text { Std. } \\
\text { Deviation }\end{array}$ \\
\hline SCS & .87 & 33.03 & 7.34 & 34.58 & 7.58 \\
BIS & .79 & 15.27 & 2.87 & 13.42 & 3.11 \\
RR & .70 & 8.56 & 1.90 & 8.32 & 1.69 \\
Drive & .82 & 9.24 & 2.32 & 9.70 & 2.11 \\
FS & .64 & 8.77 & 1.83 & 8.96 & 1.81 \\
Age & & 35.23 & 10.11 & 36.32 & 11.68 \\
\hline
\end{tabular}

SCS Self-Concealment Scale, BIS Behavioral Inhibition Scale, RR Reward Responsiveness Scale, FS Fun Seeking Scale 
Table 2

Correlation matrixes for males and females.

\begin{tabular}{llllll} 
Females & & & & \\
\hline Measure & SCS & BIS & RR & Drive & FS \\
\hline SCS & -- & -- & -- & -- & -- \\
BIS & $.243^{* *}$ & -- & -- & -- & -- \\
RR & -.046 & $.300^{* *}$ & -- & -- & -- \\
Drive & .042 & .031 & $.457^{* *}$ & -- & -- \\
FS & -.050 & .006 & $.500^{* *}$ & $.423 * *$ & -- \\
\hline & & & & & FS \\
Males & SCS & BIS & RR & Drive & - \\
\hline Measure & -- & -- & -- & -- & -- \\
\hline SCS & $.279 * *$ & -- & -- & -- & -- \\
BIS & .052 & $.242^{*}$ & -- & -- & -- \\
RR & .129 & -.156 & $.470 * *$ & -- & -- \\
Drive & $.290 * *$ & -.046 & $.479 * *$ & $.473 * *$ & \\
FS & & & & & \\
\hline
\end{tabular}

SCS Self-Concealment Scale, BIS Behavioral Inhibition Scale, RR Reward Responsiveness Scale, FS Fun Seeking Scale

**Correlation is significant at the 0.01 level (2-tailed)

* Correlation is significant at the 0.05 level (2-tailed) 


\section{Table 3}

Multiple regression tables with SCS as the dependent variable.

Model \& ANOVA summary

\begin{tabular}{|c|c|c|c|c|c|c|c|c|}
\hline Gender & Model & $R^{2}$ & $\operatorname{Adj} R^{2}$ & $R^{2}$ Change & $F$ Change & Sig. F Change & $F$ & Sig. \\
\hline Female & $1^{\mathrm{a}}$ & .059 & .053 & .059 & 9.553 & .002 & 9.553 & .002 \\
\hline Male & $1^{\mathrm{b}}$ & .084 & .074 & .084 & 8.626 & .004 & 8.626 & .004 \\
\hline & $\frac{2^{c}}{3^{d}}$ & $\begin{array}{l}.170 \\
.208\end{array}$ & $\begin{array}{l}.152 \\
.182\end{array}$ & $\begin{array}{l}.086 \\
.038\end{array}$ & $\begin{array}{l}9.585 \\
4.442\end{array}$ & $\begin{array}{l}.003 \\
.038\end{array}$ & \begin{tabular}{|l|}
9.499 \\
8.048 \\
\end{tabular} & $\begin{array}{l}.000 \\
.000\end{array}$ \\
\hline
\end{tabular}

\section{Coefficients table summary}

\begin{tabular}{|c|c|c|c|c|c|c|c|c|c|}
\hline \multirow[b]{2}{*}{ Gender } & \multirow[b]{2}{*}{ Model } & & \multicolumn{2}{|c|}{ Unstd. Coefficients } & \multirow{2}{*}{$\begin{array}{c}\text { Std. Coefficienets } \\
B\end{array}$} & \multirow[b]{2}{*}{$t$} & \multirow[b]{2}{*}{ Sig. } & \multirow[b]{2}{*}{ Zero-order } & \multirow[b]{2}{*}{ Partial } \\
\hline & & & $B$ & Std. Error & & & & & \\
\hline \multicolumn{10}{|l|}{ Female } \\
\hline & $1^{\mathrm{a}}$ & BIS & .593 & .192 & .243 & 3.091 & .002 & .243 & .243 \\
\hline \multicolumn{10}{|l|}{ Male } \\
\hline & $1^{b}$ & FS & 1.159 & .395 & .290 & 2.937 & .004 & .290 & .290 \\
\hline & $2^{c}$ & BIS & .747 & .241 & .293 & 3.096 & .003 & .279 & .306 \\
\hline & & $\mathrm{FS}$ & 1.213 & .378 & .303 & 3.207 & .002 & .290 & .316 \\
\hline & $3^{d}$ & BIS & .905 & .249 & .355 & 3.461 & .000 & .279 & .355 \\
\hline & & $\mathrm{FS}$ & 1.672 & .430 & .418 & 3.883 & .000 & .290 & .375 \\
\hline & & $\mathrm{RR}$ & -.903 & .428 & -.234 & -2.108 & .038 & .052 & -.215 \\
\hline
\end{tabular}

SCS Self-Concealment Scale, BIS Behavioral Inhibition Scale, RR Reward Responsiveness Scale, FS Fun Seeking Scale;

a predictors: BIS, ${ }^{b}$ predictors: FS, ${ }^{c}$ predictors: BIS and FS, ${ }^{\mathrm{d}}$ predictors: BIS, FS, and RR 